\title{
Tailoring $\mathrm{Cu}^{+}$for $\mathrm{Ga}^{3+}$ Cation Exchange in $\mathrm{Cu}_{2-x} \mathrm{~S}$ and $\mathrm{CuInS}_{2}$ Nanocrystals by Controlling the Ga Precursor Chemistry
}

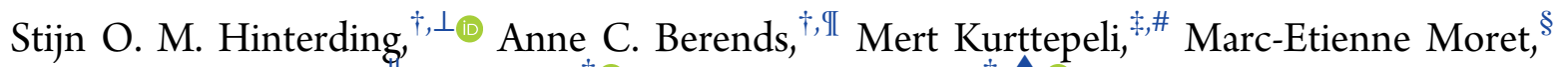

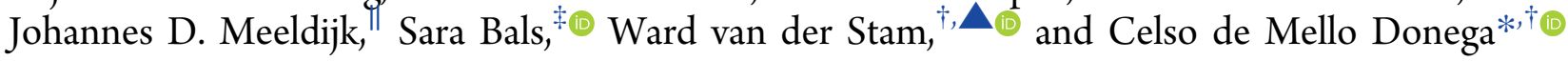

${ }^{\dagger}$ Condensed Matter and Interfaces, Debye Institute for Nanomaterials Science, Utrecht University, P.O. Box 80000, 3508 TA Utrecht, The Netherlands

${ }^{\ddagger}$ Electron Microscopy for Materials Science (EMAT), University of Antwerp, Groenenborgerlaan 171, B-2020 Antwerp, Belgium ${ }^{\S}$ Organic Chemistry and Catalysis, Debye Institute for Nanomaterials Science, Utrecht University, Universiteitsweg 99,3584 CG Utrecht, The Netherlands

"Electron Microscopy Utrecht, Debye Institute for Nanomaterials Science, Utrecht University, 3584 CH Utrecht, The Netherlands Web-Enhanced Feature S Supporting Information

ABSTRACT: Nanoscale cation exchange (CE) has resulted in colloidal nanomaterials that are unattainable by direct synthesis methods. Aliovalent $\mathrm{CE}$ is complex and synthetically challenging because the exchange of an unequal number of host and guest cations is required to maintain charge balance. An approach to control aliovalent $\mathrm{CE}$ reactions is the use of a single reactant to both supply the guest cation and extract the host cation. Here, we study the application of $\mathrm{GaCl}_{3}-\mathrm{L}$ complexes $[\mathrm{L}=$ trioctylphosphine (TOP),

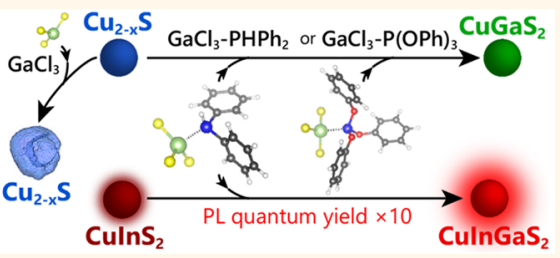
triphenylphosphite (TPP), diphenylphosphine (DPP)] as reactants in the exchange of $\mathrm{Cu}^{+}$for $\mathrm{Ga}^{3+}$ in $\mathrm{Cu}_{2-x} \mathrm{~S}$ nanocrystals. We find that noncomplexed $\mathrm{GaCl}_{3}$ etches the nanocrystals by $\mathrm{S}^{2-}$ extraction, whereas $\mathrm{GaCl}_{3}-\mathrm{TOP}$ is unreactive. Successful exchange of $\mathrm{Cu}^{+}$for $\mathrm{Ga}^{3+}$ is only possible when $\mathrm{GaCl}_{3}$ is complexed with either TPP or DPP. This is attributed to the pivotal role of the $\mathrm{Cu}_{2-x} \mathrm{~S}-\mathrm{GaCl}_{3}-\mathrm{L}$ activated complex that forms at the surface of the nanocrystal at the onset of the $\mathrm{CE}$ reaction, which must be such that simultaneous $\mathrm{Ga}^{3+}$ insertion and $\mathrm{Cu}^{+}$extraction can occur. This requisite is only met if $\mathrm{GaCl}_{3}$ is bound to a phosphine ligand, with a moderate bond strength, to allow facile dissociation of the complex at the nanocrystal surface. The general validity of this mechanism is demonstrated by using $\mathrm{GaCl}_{3}-\mathrm{DPP}$ to convert $\mathrm{CuInS}_{2}$ into $(\mathrm{Cu}, \mathrm{Ga}, \mathrm{In}) \mathrm{S}_{2}$ nanocrystals, which increases the photoluminescence quantum yield 10-fold, while blue-shifting the photoluminescence into the NIR biological window. This highlights the general applicability of the mechanistic insights provided by our work.

KEYWORDS: semiconductor nanocrystals, cation exchange, copper sulfide, copper gallium sulfide, copper indium sulfide, copper indium gallium sulfide

ompound copper chalcogenide nanocrystals (NCs) offer a promising alternative to the widely studied CdX and PbX NCs (X = S, Se, Te), as they consist of less toxic elements and display exciting optoelectronic properties, such as photoluminescence $(\mathrm{PL})$ tunability in the visible to the near-infrared (NIR) spectral window and localized surface plasmon resonances (LSPR) in the NIR. ${ }^{1-4}$ Another advantage of these nanomaterials is the wide range of compositions that can be obtained, ranging from binary to multinary compounds with up to five different elements. ${ }^{1-3}$ This makes them a versatile class of materials, offering ample opportunities for property engineering. ${ }^{1-3,5}$ However, some morphologies and compositions are not easily accessible by direct approaches due to synthetic limitations, such as the lack of suitable precursors for multinary compounds. ${ }^{1}$ Nanoscale cation exchange (CE) has emerged as a promising post- synthetic tool to circumvent these limitations, providing pathways to NCs and hetero-NCs with compositions, morphologies, crystal structures, and heteroarchitectures that would otherwise remain unavailable. ${ }^{5-8}$ The extent of the CE (ranging from doping, e.g., Ag: $\mathrm{CdSe} \mathrm{NCs},{ }^{9} \mathrm{Zn}: \mathrm{CsPbBr}_{3} \mathrm{NCs},{ }^{10}$ $\mathrm{Mn}: \mathrm{ZnTe}$ magic-size clusters, ${ }^{11}$ to full replacement $)^{5-8}$ and the elemental distribution profile of the product NCs (i.e., homogeneous or gradient alloys, e.g., $(\mathrm{Cd}, \mathrm{Zn}) \mathrm{Se} \mathrm{NCs},{ }^{12}$ or heterostructured NCs, e.g., $\mathrm{ZnSe} / \mathrm{CdSe},{ }^{12} \mathrm{PbSe} / \mathrm{CdSe}{ }^{13}$ core/ shell quantum dots) depends on a number of physicochemical properties, such as the miscibility of the parent and product

Received: July 7, 2019

Accepted: October 16, 2019

Published: October 16, 2019 


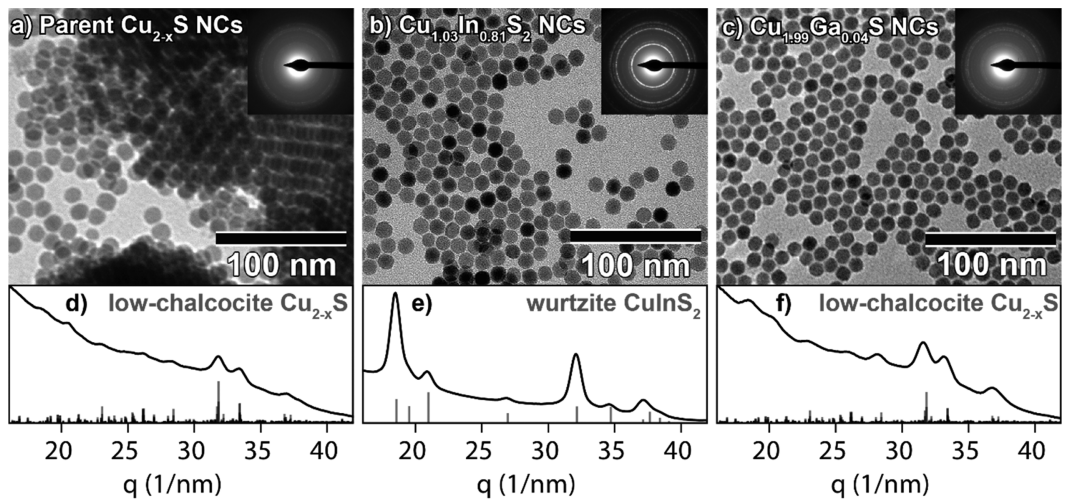

Figure 1. TEM images of (a) parent $\mathrm{Cu}_{2-x} \mathrm{~S}$ bifrustum NCs, (b) product $\mathrm{Cu}_{1.03} \mathrm{In}_{0.81} \mathrm{~S}_{2}$ (CIS) bifrustum NCs, after reaction with InCl ${ }_{3}-\mathrm{TOP}$ at $100{ }^{\circ} \mathrm{C}$, and (c) $\mathrm{Cu}_{1.99} \mathrm{Ga}_{0.04} \mathrm{~S}$ nanocrystals, after reaction with $\mathrm{GaCl}_{3}-\mathrm{TOP}$ at $100{ }^{\circ} \mathrm{C}$. Top-right insets display the corresponding ED pattern. Bottom panels show azimuthally integrated ED (PED) patterns of (d) parent low-chalcocite $\mathrm{Cu}_{2-x} \mathrm{~S}$ nanocrystals, (e) product wurtzite CIS nanocrystals, and (f) product low-chalcocite $\mathrm{Cu}_{1.99} \mathrm{Ga}_{0.04} \mathrm{~S}$ nanocrystals. Reference bars in (d,f) are calculated patterns based on the low-chalcocite $\mathrm{Cu}_{2-x} \mathrm{~S}$ crystal structure described in ref 34. Reference bars in (e) were obtained from JCPDS PDF-card 01-077-9459 for wurtzite CIS.

phases and the diffusion rates of the incoming and outgoing cations within the NCs and can be tailored by adjusting reaction variables, such as reaction temperature and concentration of guest cations in solution. ${ }^{5-13}$

In isovalent $\mathrm{CE}$, such as $\mathrm{Zn}^{2+}$ for $\mathrm{Cd}^{2+}$ exchange in $\mathrm{ZnSe}$ $\mathrm{NCs}^{12}$ and $\mathrm{Pb}^{2+}$ for $\mathrm{Cd}^{2+}$ in $\mathrm{PbX} \mathrm{NCs},{ }^{13-15}$ a direct place exchange reaction occurs at the surface of the template NCs, through which the outgoing host cation and the incoming guest cation swap places (i.e., the guest cation is incorporated in the NC, while the host cation forms a complex with the ligand molecule that was carrying the guest cation). ${ }^{12}$ This is in contrast with aliovalent $\mathrm{CE}$, such as $\mathrm{Cu}^{+}$for $\mathrm{In}^{3+}$ in $\mathrm{Cu}_{2-x} \mathrm{~S}$ $\mathrm{NCs}^{16}$ or $\mathrm{Cd}^{2+}$ for $\mathrm{Ag}^{+}$in $\mathrm{CdSe},{ }^{5,9,17}$ which typically occurs through two separate chemical pathways. ${ }^{5-8,16}$ This makes balancing the in- and outgoing diffusion rates challenging. An approach to better control aliovalent CE reactions is the use of a single precursor, which both provides the guest cation and extracts the host cation. In the case of the $\mathrm{Cu}^{+}$for $\mathrm{In}^{3+}$ exchange, a stoichiometric $\mathrm{InCl}_{3}-$ trioctylphosphine complex has been shown to be a suitable precursor, even allowing for topotactic sequential $\mathrm{CE}$ (viz., $\mathrm{Cd}^{2+}$ for $\mathrm{Cu}^{+}$, followed by partial $\mathrm{Cu}^{+}$for $\mathrm{In}^{3+}$ ) in large and complex anisotropic NCs such as $\mathrm{CdSe} / \mathrm{CdS}$ dot-in-rod nanorods, with preservation of the size, shape, and heterostructure of the template NCs in the product $\mathrm{CuInSe}_{2} / \mathrm{CuInS}_{2}$ dot-in-rod nanorods. ${ }^{18}$ The strict control over the $\mathrm{CE}$ rates provided by this approach has been recently exploited to fabricate air-stable $\mathrm{CuInSe}_{2} \mathrm{NC}$ transistors by postdeposition sequential CE. ${ }^{19}$ Here, we extend the single precursor approach to the exchange of $\mathrm{Cu}^{+}$for $\mathrm{Ga}^{3+}$ in $\mathrm{Cu}_{2-x} \mathrm{~S}$ and $\mathrm{CuInS} \mathrm{NCs}_{2} \mathrm{NC}$ using stoichiometric $\mathrm{GaCl}_{3}-$ phosphine complexes to simultaneously deliver $\mathrm{Ga}^{3+}$ and extract $\mathrm{Cu}^{+}$. Our choice is motivated by the fact that $\mathrm{CuGaS}_{2}$ (CGS) and $\mathrm{Cu}(\mathrm{In}, \mathrm{Ga}) \mathrm{S}_{2}$ (CIGS) exhibit interesting optoelectronic properties, which make them promising materials for applications in photocatalysis, ${ }^{20,21}$ light-emitting devices, ${ }^{22,23}$ and photovoltaics. ${ }^{24-27}$ Moreover, studies of $\mathrm{Cu}^{+}$for $\mathrm{Ga}^{3+}$ and $\mathrm{In}^{3+}$ for $\mathrm{Ga}^{3+}$ cation exchange are scarce. ${ }^{28-30}$ Although $\mathrm{Ga}^{3+}$ and $\mathrm{In}^{3+}$ are both trivalent cations of group IIIA metals, they have significantly different ionic radii $\left(r_{\mathrm{Ga}^{3+}}=47 \mathrm{pm}, r_{\mathrm{In}^{3+}}=62\right.$ $\mathrm{pm})^{31}$ and Lewis acidity $\left(\eta_{\mathrm{Ga}^{3+}}=17 \mathrm{eV}, \eta_{\mathrm{In}^{3+}}=13 \mathrm{eV}\right)^{32}$ and are thus expected to behave differently in cation exchange reactions. Our study thus offers an ideal testbed to investigate the relationship between the chemistry of the metal chloride- phosphine complexes and the outcome of cation exchange reactions in $\mathrm{Cu}$ chalcogenide NCs.

We investigated different $\mathrm{GaCl}_{3}-\mathrm{L}$ Lewis acid-base adduct complexes $[\mathrm{L}=$ trioctylphosphine (TOP), triphenylphosphite (TPP), and diphenylphosphine DPP)] as reagents for the exchange of $\mathrm{Cu}^{+}$for $\mathrm{Ga}^{3+}$ and found that the choice of ligand has a profound impact on the reaction outcome. Noncomplexed $\mathrm{GaCl}_{3}$ is a strong Lewis acid that yields hollow NCs through etching by sulfide extraction, whereas the complex $\mathrm{GaCl}_{3}$-trioctylphosphine leads to neither etching nor cation exchange. In contrast, both $\mathrm{GaCl}_{3}$-triphenylphosphite and $\mathrm{GaCl}_{3}$-diphenylphosphine successfully converted $\mathrm{Cu}_{2-x} \mathrm{~S}$ NCs in $\mathrm{CuGaS}_{2}$ NCs through $\mathrm{Cu}^{+}$for $\mathrm{Ga}^{3+}$ exchange. These different reactivities are attributed to the stability and geometry of the activated $\mathrm{Cu}_{2-x} \mathrm{~S}-\mathrm{GaCl}_{3}-\mathrm{L}$ complex that must be formed at the surface of the NCs prior to the cation exchange. Density functional theory (DFT) calculations show that, in these complexes, the $\mathrm{Ga}-\mathrm{P}$ bond strength decreases with increasing electron-withdrawing nature of the side groups on the phosphine ligands (i.e., the $\mathrm{Ga}-\mathrm{P}$ bond strength $\varepsilon$ follows the trend $\left.\varepsilon_{\mathrm{GaCl}_{3}-\mathrm{TOP}}>\varepsilon_{\mathrm{GaCl}_{3} \text {-DPP }}>\varepsilon_{\mathrm{GaCl}_{3}-\mathrm{TPP}}\right)$. Complexing $\mathrm{GaCl}_{3}$ with DPP or TPP lowers the activation energy barrier for the $\mathrm{CE}$ reaction, while kinetically favoring the $\mathrm{Cu}^{+}$for $\mathrm{Ga}^{3+}$ place exchange over the sulfide extraction. These insights were used to successfully convert $\mathrm{CuInS}_{2} \mathrm{NCs}$ into $\mathrm{Cu}$-poor $(\mathrm{Cu}, \mathrm{In}, \mathrm{Ga}) \mathrm{S}_{2}$ NCs through $\mathrm{Cu}^{+}$for $\mathrm{Ga}^{3+}$ exchange, yielding NCs with vastly improved photoluminescence quantum yields with respect to the parent NCs. The findings presented in this work are thus generally applicable, resulting in nanomaterials with combinations of size, shape, composition, and crystal structure that are not directly accessible by conventional synthesis routes.

\section{RESULTS AND DISCUSSION}

Stoichiometric $\operatorname{InCl}_{3}-$ TOP and $\mathrm{GaCl}_{3}-\mathrm{TOP}$ as Reactants for Cation Exchange in $\mathrm{Cu}_{2-x} \mathrm{~S} \mathrm{NCs}$. Throughout this work, low-chalcocite $12 \mathrm{~nm} \mathrm{Cu}_{2-x} \mathrm{~S}(x<0.04)$ bifrustum NCs are used as parent $\mathrm{NCs}$ to investigate the $\mathrm{Cu}^{+}$for $\mathrm{Ga}^{3+}$ cation exchange reaction. For comparison, these NCs (Figure 1a,d) are converted into wurtzite $\mathrm{CuInS}_{2}$ (CIS) bifrustum NCs (Figure $1 \mathrm{~b}, \mathrm{e}$ ) by partial, self-limited $\mathrm{Cu}^{+}$for $\mathrm{In}^{3+} \mathrm{CE}$ at $100{ }^{\circ} \mathrm{C}$, using a stoichiometric $\mathrm{InCl}_{3}$-trioctylphosphine $\left(\mathrm{InCl}_{3}-\mathrm{TOP}\right)$ 


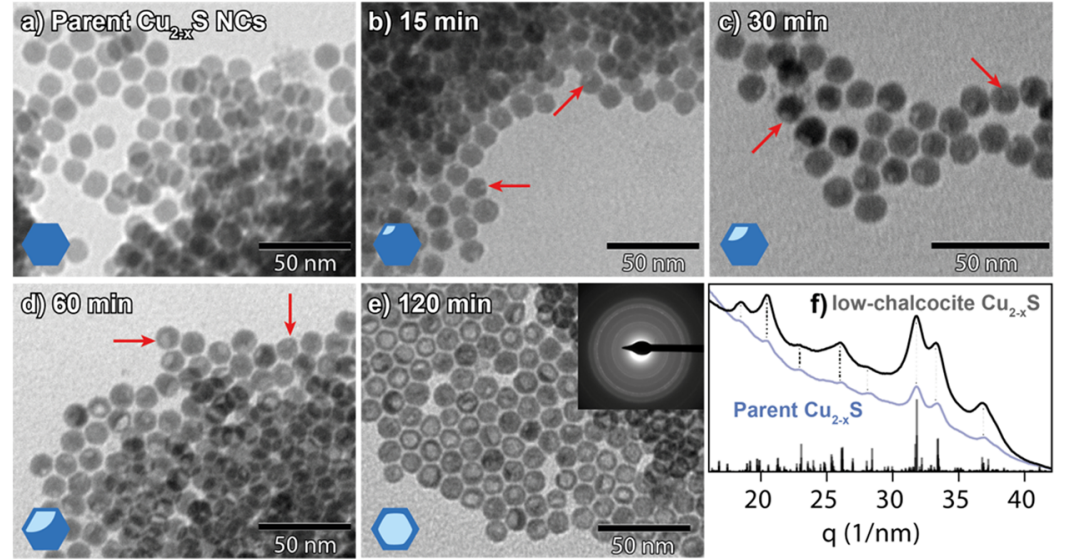

Figure 2. TEM images of (a) parent $\mathrm{Cu}_{2-x} \mathrm{~S}$ NCs and (b-e) product NCs obtained after reacting the NCs shown in $(\mathrm{a})$ with $\mathrm{GaCl}{ }_{3}$ at $30{ }^{\circ} \mathrm{C}$ for (b) $15 \mathrm{~min}$, (c) $30 \mathrm{~min}$, (d) $60 \mathrm{~min}$, and (e) $120 \mathrm{~min}$. Red arrows indicate regions of low contrast within the nanocrystals (cartoons in the lower-left corner give an impression of the observed contrast in the NCs). Top-right inset in (e) depicts an electron diffraction pattern of the corresponding sample. Panel $(f)$ is the azimuthally integrated ED pattern depicted in (e). Reference bars in (f) are calculated patterns based on the low-chalcocite $\mathrm{Cu}_{2-x} \mathrm{~S}$ crystal structure described in ref 34. The blue curve in (f) corresponds to the PED pattern of the parent $\mathrm{Cu}_{2-x} \mathrm{~S}$ nanocrystals. Dotted lines serve as guides for the eye.

Lewis acid-base adduct as precursor, as previously reported by our group. ${ }^{18}$ The transformation from low chalcocite to wurtzite is evidenced by the electron diffraction (ED) patterns (Figure la,b,d,e). The powder ED (PED) pattern obtained after azimuthal integration of the 2D ED pattern of the product NCs (Figure 1e) corresponds well to the reference pattern of wurtzite CIS. The shape and size of the NCs are preserved after the reaction (Supporting Information, Figure S1), confirming the topotactic nature of the $\mathrm{Cu}^{+}$for $\mathrm{In}^{3+} \mathrm{CE}$ reaction. Energy-dispersive X-ray spectroscopy (EDS) measurements further confirm the conversion of $\mathrm{Cu}_{2-x} \mathrm{~S}$ NCs into ternary CIS NCs $(\mathrm{Cu} / \mathrm{In}=1.00: 0.79$; Supporting Information, Figure S2). Compared to the $\mathrm{Cu}_{2-x} \mathrm{~S}$ parent NCs, the product CIS NCs no longer exhibit a LSPR absorption band in the NIR (Supporting Information, Figure S3a,b). The absorption spectrum of the CIS NCs agrees well with spectra reported in the literature. ${ }^{33}$ In contrast, the use of the stoichiometric $\mathrm{GaCl}_{3}$-TOP Lewis acid-base adduct as a precursor does not lead to any significant change in the composition $(\mathrm{Cu} / \mathrm{Ga}=$ 1.00:0.02, Supporting Information, Figure S4), crystal structure, size, and shape of the NCs (Figure 1c,f). The absorption spectrum of NCs obtained after reaction with $\mathrm{GaCl}_{3}$-TOP exhibits little to no LSPR band (Supporting Information, Figure S3c), which indicates the absence of excess free holes in these NCs, due to (limited) reduction at the NC surface.

Reaction of Noncomplexed $\mathrm{GaCl}_{3}$ with $\mathrm{Cu}_{2-x} \mathrm{~S}$ NCs. Clearly, the $\mathrm{Cu}^{+}$for $\mathrm{Ga}^{3+} \mathrm{CE}$ does not significantly occur when $\mathrm{GaCl}_{3}$-TOP is used as the reactant under the same conditions that successfully lead to $\mathrm{Cu}^{+}$for $\mathrm{In}^{3+} \mathrm{CE}$ using $\mathrm{InCl}_{3}-\mathrm{TOP}$. Therefore, other $\mathrm{Ga}$ precursors were examined, starting with the simplest possible case: $\mathrm{GaCl}_{3}$ dissolved in neat toluene. The reaction with $\mathrm{GaCl}_{3}$ at the same temperature used with $\mathrm{GaCl}_{3}$-TOP $\left(100{ }^{\circ} \mathrm{C}\right)$ was found to severely deteriorate the NCs (Supporting Information, Figure S5). To minimize the degradation, the temporal evolution of this reaction was studied at a lower temperature $\left(30{ }^{\circ} \mathrm{C}\right.$ ) (Figure $\left.2 \mathrm{~b}-\mathrm{e}\right)$. The TEM images of the product NCs show that, despite the lower reaction temperature, a low-contrast spot appears in the NCs already after $15 \mathrm{~min}$ of reaction (Figure $2 \mathrm{~b}$, red arrows) and increases in size over time (Figure $2 \mathrm{c}-\mathrm{e}$ ). The PED pattern shows that the crystal structure of the NCs remains lowchalcocite $\mathrm{Cu}_{2-x} \mathrm{~S}$, even after $120 \mathrm{~min}$ of reaction (Figure 2f), despite the dramatic morphological changes (Figure 2e). After $120 \mathrm{~min}$ of reaction, these NCs no longer exhibit an LSPR absorption band (Supporting Information, Figure S3f), presumably due to their poorly defined shape.

To determine the nature of the low contrast region and its position within the particles, high-angle annular dark-field scanning transmission microscopy (HAADF-STEM) tomography measurements were performed. Visualizations of the 3D reconstructed volumes of NCs after different reaction times are shown in Figure 3. Animated versions of the tomograms are also provided in the web-enhanced movies 1,2 , and 3 . The tomography measurements show that, after 15 min of reaction with $\mathrm{GaCl}_{3}$, a small cavity is present at the surface of some $\mathrm{Cu}_{2-x} \mathrm{~S}$ NCs (Figure $3 \mathrm{a}$ ) and increases in size as the reaction progresses (Figure 3b,c). Acquired orthoslices, which were used to reconstruct the $3 \mathrm{D}$ morphologies, are displayed in Figure $3 \mathrm{~d}-\mathrm{f}$. These measurements indicate that the brighter regions observed in TEM images coincide with cavities at the surface of the NCs. The cavities appear to form at the surface of the NCs at early reaction stages and subsequently grow inward over time. A small portion of the NCs (indicated by red arrows in Figure 3) appears to be hollow, without an obvious opening at the surface.

These observations bear similarities with previous reports on hollow nanoparticles, whose formation has been ascribed to the nanoscale Kirkendall effect, ${ }^{35,36}$ which involves an imbalance between outward and inward diffusion fluxes during the chemical conversion of a NC into a different material through reaction with a reactant present in solution. The surface of the parent NC is first converted into a shell of the product material by reaction with a species present in solution, after which further conversion can only take place through solid-state diffusion of the reactant species through the NC. ${ }^{35}$ In case the outward diffusion rate is faster than the inward diffusion rate, there is a net flow of material going out of the NC, leaving vacancies behind. ${ }^{35}$ Condensation of these vacancies gives rise to voids that eventually collect in a central void in the NCs. ${ }^{35}$ The nanoscale Kirkendall process has also been recently proposed as an explanation for the conversion of 

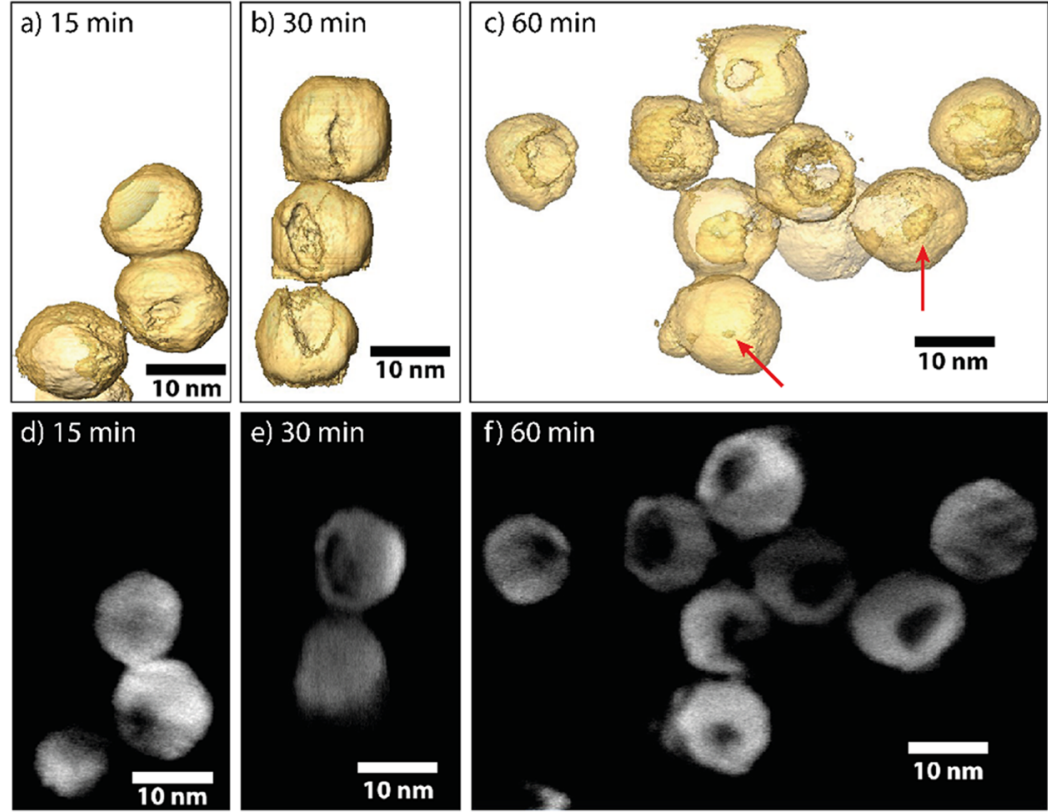

Figure 3. 3D characterization of tomographic visualization of the $\mathrm{Cu}_{2-x} \mathrm{~S}$ bifrustum $\mathrm{NCs}$ after reaction with $\mathrm{GaCl}_{3}$ at $30{ }^{\circ} \mathrm{C}$ for (a) $15 \mathrm{~min}$, (b) $30 \mathrm{~min}$, and (c) $60 \mathrm{~min}$. After $15 \mathrm{~min}$, only a small dimple is present at the surface of the NCs. After longer reaction times, these cavities are found to be larger. Red arrows indicate hollow NCs without an apparent opening at the surface. (d-f) Orthoslices used to reconstruct the 3D morphologies presented in $(a-c)$. Animated (rotating) versions of the models depicted in panels $(a-c)$ are provided.

$\mathrm{Cu}_{2-x} \mathrm{~S}$ nanoplatelets into $\mathrm{CuInS}_{2}$ nanorings through partial $\mathrm{Cu}^{+}$for $\mathrm{In}^{3+} \mathrm{CE}^{37}$ Our observations, however, are not consistent with the nanoscale Kirkendall effect, as the cavities form at the surface of the NCs and grow inward, in striking contrast with the outward growing inner voids that characterize the Kirkendall effect.

Surface erosion of the NCs and preservation of a lowchalcocite $\mathrm{Cu}_{2-x} \mathrm{~S}$ shell after the reaction with $\mathrm{GaCl}_{3}$ indicate that a reaction other than cation exchange is taking place. In the successful $\mathrm{Cu}^{+}$for $\mathrm{In}^{3+}$ cation exchange reaction using the $\mathrm{InCl}_{3}$-TOP Lewis acid-base adduct complex, TOP (a soft Lewis base) acts as $\mathrm{Cu}^{+}$extractor, ${ }^{5,18}$ likely forming $\mathrm{CuCl}-$ TOP Lewis acid-base adduct complexes. In the present reaction using noncomplexed $\mathrm{GaCl}_{3}$, there are no species present to directly extract $\mathrm{Cu}^{+}$. However, $\mathrm{GaCl}_{3}$ is a strong Lewis acid ${ }^{38,39}$ and therefore can extract $\mathrm{S}^{2-}$ from the NC as $\mathrm{S}^{2-}$ is a Lewis base. This extraction destabilizes the crystal lattice, as the $\mathrm{S}^{2-}$ anions form the framework of $\mathrm{Cu}_{2-x} \mathrm{~S} \mathrm{NCs}$, resulting in etching of the NCs and formation of cavities at the surface. The collapse of the NC framework will release $\mathrm{Cu}^{+}$ ions, which are likely stabilized in solution by binding to the chloride ions released from $\mathrm{GaCl}_{3}$ after its reaction with the NC sulfides.

Although the NCs react with a strong Lewis acid, they do not dissolve completely, even after $300 \mathrm{~min}$ (Supporting Information, Figure S6). Interestingly, in micrographs obtained using HAADF-STEM, most particles exhibit a uniform contrast after reacting for $300 \mathrm{~min}$ (Supporting Information, Figure S6e). This uniform contrast indicates that the previously formed cavities are filled with new material. EDS elemental maps show that this material consists mostly of gallium. These observations suggest that Ga-containing monomers, formed upon extraction of $\mathrm{S}^{2-}$ by $\mathrm{GaCl}_{3}$, precipitate inside the $\mathrm{NC}$ cavities after longer reaction times. This refilling of the cavities likely blocks further reactions on the NC surface, preventing further dissolution.
Tailoring the Ga Precursor Chemistry To Boost the $\mathrm{Cu}^{+}$for $\mathrm{Ga}^{3+}$ Cation Exchange. We have discussed above two extreme cases of reactivity imbalance: whereas $\mathrm{GaCl}_{3}-$ TOP is too inert, hardly leading to any change in the parent $\mathrm{Cu}_{2-x} \mathrm{~S}$ NCs, noncomplexed $\mathrm{GaCl}_{3}$ is too reactive toward the sulfide anions, thereby etching the parent NCs without any significant cation exchange. In the following, we will tailor the chemistry of the $\mathrm{Ga}$ precursor complex to allow successful $\mathrm{Cu}^{+}$ for $\mathrm{Ga}^{3+}$ cation exchange.

The observation that the reactivity of the $\mathrm{GaCl}_{3}-\mathrm{TOP}$ Lewis acid-base adduct complex as a cation exchange precursor is much lower than that of the $\mathrm{InCl}_{3}-\mathrm{TOP}$ complex is surprising, considering that the metal-phosphorus bond in $\mathrm{GaCl}_{3}$-TOP should be weaker than that in $\mathrm{InCl}_{3}$-TOP as $\mathrm{Ga}^{3+}$ is a harder Lewis acid than $\operatorname{In}^{3+}(\eta=17$ and $13 \mathrm{eV}$, respectively), ${ }^{32}$ whereas TOP is a soft Lewis base $(\eta \approx 6$ eV). ${ }^{5,40}$ This implies that other variables are more relevant in determining the $\mathrm{Cu}^{+}$for $\mathrm{Ga}^{3+}$ cation exchange rates and prompted us to explore the influence of the nature of the phosphine ligand on the cation exchange reaction by using triphenylphosphite and diphenylphosphine as ligands for $\mathrm{GaCl}_{3}$ (Figure 4b,c). The coordination behavior of a phosphine ligand with respect to a metal center is determined by its steric and electronic properties. ${ }^{41,42}$ The most frequently used parameter to quantify the steric properties of phosphines is the Tolman cone angle, defined as the apex angle of a cylindrical cone with origin $2.28 \AA$ from the center of the phosphorus atom, whose sides just touch the Van der Waals surfaces of the outermost atoms of the organic substituents. ${ }^{41}$ The three phosphine ligands used in the present work have significantly different electronic properties and total molecular volume, but their Tolman cone angles are essentially the same: $128^{\circ}$ for both DPP and TPP and $132^{\circ}$ for TOP. ${ }^{41}$ The value for TOP is taken to be the same as that reported by Tolman for other tertiary alkylphosphines, such as tri- $n$-butylphosphine, although a recent work has estimated it to be $128^{\circ} .{ }^{40}$ Steric 


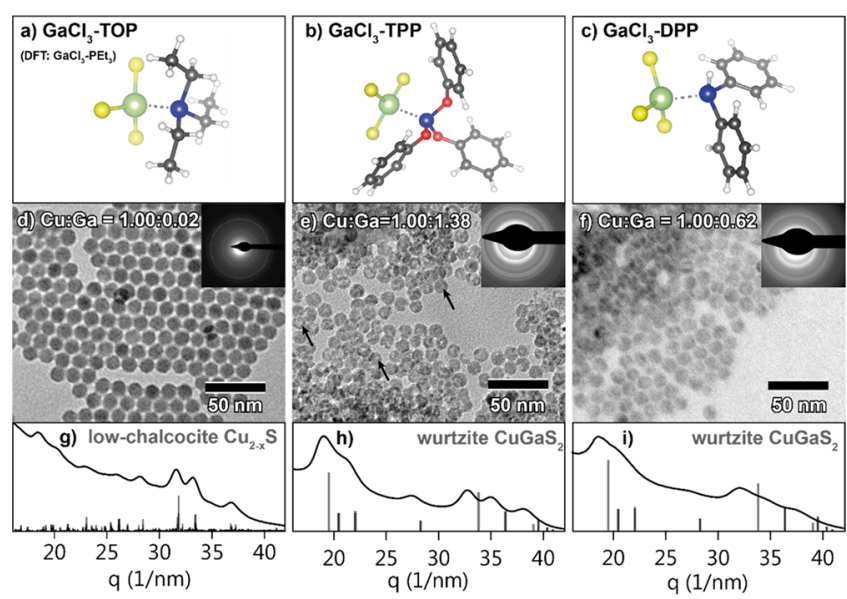

Figure 4. (Top row) Ground-state geometries of three $\mathrm{GaCl}_{3}-$ phosphine complexes obtained from DFT calculations (see below): (a) $\mathrm{GaCl}_{3}$ complexed with triethylphosphine, used as model for $\mathrm{GaCl}_{3}$ complexed with trioctylphosphine $\left(\mathrm{GaCl}_{3}-\mathrm{TOP}\right)$, (b) $\mathrm{GaCl}_{3}$ complexed with triphenylphosphite $\left(\mathrm{GaCl}_{3}-\mathrm{TPP}\right)$, and (c) $\mathrm{GaCl}_{3}$ complexed with diphenylphosphine $\left(\mathrm{GaCl}_{3}-\mathrm{DPP}\right)$. (Middle row) TEM images of product NCs obtained after reaction of $\mathrm{Cu}_{2-x} \mathrm{~S}$ NCs with (d) $\mathrm{GaCl}_{3}-\mathrm{TOP}$ at $100{ }^{\circ} \mathrm{C}$, (e) $\mathrm{GaCl}_{3}-\mathrm{TPP}$ at $100{ }^{\circ} \mathrm{C}$, and (f) $\mathrm{GaCl}_{3}-\mathrm{DPP}$ at $50{ }^{\circ} \mathrm{C}$. Black arrows indicate intraparticle contrast in the NCs reacted with $\mathrm{GaCl}_{3}-\mathrm{TPP}$. Topright insets show the corresponding ED patterns. Bottom row ( $\mathrm{g}-$ i) shows the corresponding azimuthally integrated ED patterns. Reference bars in $(h, i)$ are calculated patterns based on the wurtzite $\mathrm{CuGaS}_{2}$ crystals structure, ${ }^{44}$ and reference bars in (g) are based on the low-chalcocite $\mathrm{Cu}_{2-x} \mathrm{~S}$ crystal structure. ${ }^{34}$

effects are thus not expected to play a significant role in the cation exchange reactions investigated in our work. The electronic properties of phosphines are determined by their $\sigma$ donor ability and $\pi$-acceptor strength as they bind to metals by a combination of $\sigma$-donation from the lone pair of the $\mathrm{P}$ atom and $\pi$-back bonding from the $\mathrm{d}$ orbitals of the metal into their empty $\mathrm{P}-\mathrm{R} \sigma^{*}$ molecular orbital ( $\mathrm{R}=$ organic substituent). ${ }^{4,42}$ More electronegative (i.e., electron-withdrawing) substituents on the phosphorus atom decrease the basicity and $\sigma$-donating ability of the phosphine, while increasing its $\pi$ acceptor strength. ${ }^{40-43}$ This effect is due to the decrease of the electronic density on the phosphorus atom and increase of the s-character of the lone electron pair. ${ }^{41,42}$ An increase in electronegativity of the substituents on the phosphorus atom should lead to weaker bonding to the metal, as should be the case for $\mathrm{GaCl}_{3}-\mathrm{TPP}$ and $\mathrm{GaCl}_{3}-\mathrm{DPP}$ compared to $\mathrm{GaCl}_{3}-$ TOP.

Indeed, the use of both $\mathrm{GaCl}_{3}-\mathrm{TPP}$ and $\mathrm{GaCl}_{3}-\mathrm{DPP}$ as reactants results in successful $\mathrm{CE}$ reactions even after reaction times much shorter than those used for $\mathrm{GaCl}_{3}-\mathrm{TOP}(1 \mathrm{~h}$ instead of $12 \mathrm{~h}$, at the same temperature), as clearly demonstrated by EDS analysis of the product NCs obtained after reaction with $\mathrm{GaCl}_{3}-\mathrm{TPP}$ and $\mathrm{GaCl}_{3}-\mathrm{DPP}$ at $100{ }^{\circ} \mathrm{C}$, which reveals $\mathrm{Cu} / \mathrm{Ga}$ ratios of $1.00: 1.38$ and 1.00:1.48, respectively (Supporting Information, Figures S7 and S8). The NCs that reacted with $\mathrm{GaCl}_{3}-\mathrm{TPP}$ are partially deformed and exhibit intraparticle contrast in TEM images (Figure $4 \mathrm{e}$, indicated by black arrows), similar to the NCs that reacted with $\mathrm{GaCl}_{3}$ (see Figures 2 and 3). The NCs that reacted with $\mathrm{GaCl}_{3}$-DPP form agglomerates (Supporting Information, Figure S9), which is likely due to displacement of the original organic capping ligands (dodecanethiol) with DPP during the $\mathrm{CE}$ reaction. DPP is a relatively small molecule and thus poorly suitable as a steric stabilizer. In comparison, the NCs cluster less after reaction with $\mathrm{GaCl}_{3}-\mathrm{TPP}$ as triphenylphosphite is bulky enough to provide steric stabilization. To increase the colloidal stability of the $\mathrm{NCs}$ reacted with $\mathrm{GaCl}_{3}-\mathrm{DPP}$, oleylamine (OLAM) was added to the reaction mixture and a lower reaction temperature $\left(50{ }^{\circ} \mathrm{C}\right)$ was employed, which indeed inhibited NC agglomeration (Figure 4f). However, under these milder reaction conditions, the $\mathrm{Cu}^{+}$for $\mathrm{Ga}^{3+}$ exchange proceeds to a lesser extent, as shown by EDS analysis $(\mathrm{Cu} / \mathrm{Ga}$ ratio of 1.00:0.62, Supporting Information, Figure S10). The PED pattern (Figure 4e,h) of the NCs reacted with $\mathrm{GaCl}_{3}$-TPP corresponds to the wurtzite crystal structure, confirming that $\mathrm{Cu}^{+}$for $\mathrm{Ga}^{3+} \mathrm{CE}$ has indeed taken place. Interestingly, the peaks in the ED pattern are shifted to lower $q$ values compared to those of the reference wurtzite CGS, indicating that the product CGS NCs have a larger lattice constant than the reference. This observation will be discussed in more detail below. The PED pattern (Figure 4f,i) of the NCs reacted with $\mathrm{GaCl}_{3}-\mathrm{DPP}$ exhibits broad, poorly defined peaks, indicating that these particles have partially lost their crystallinity during the $\mathrm{CE}$ procedure, which precludes a definitive assignment of the crystal structure. The NCs reacted with $\mathrm{GaCl}_{3}-\mathrm{TPP}$ and $\mathrm{GaCl}_{3}-\mathrm{DPP}$ are both smaller than the parent $\mathrm{Cu}_{2-x} \mathrm{~S}$ NCs (diameters $=10.8 \pm 1.0,11.1 \pm 1.1$, and $12.3 \pm 1.0 \mathrm{~nm}$, respectively, Supporting Information, Figure $\mathrm{S} 1)$. The NCs reacted with $\mathrm{GaCl}_{3}-\mathrm{TPP}$ no longer exhibit an LSPR absorption band, whereas those reacted with $\mathrm{GaCl}_{3}-$ DPP exhibit an LSPR absorption band with a reduced intensity
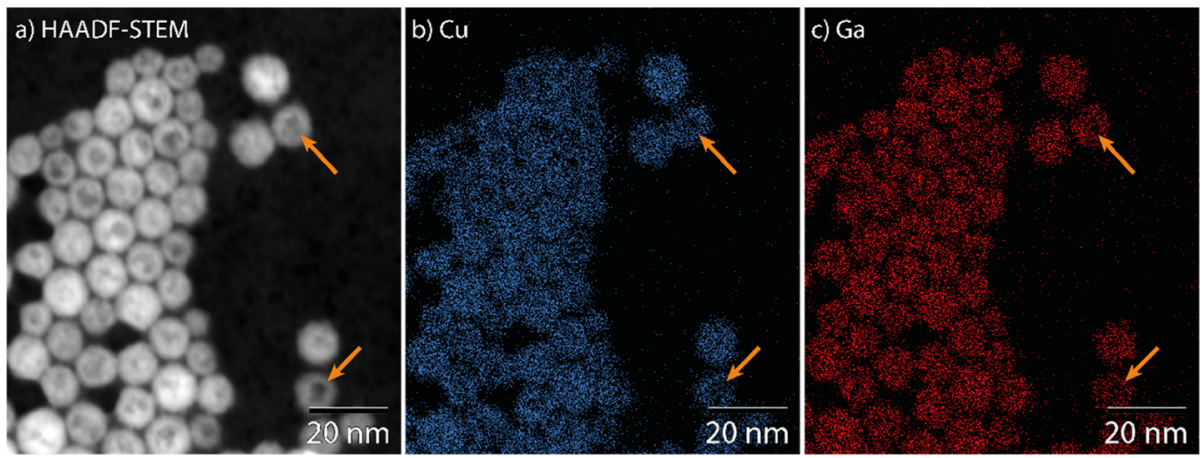

Figure 5. (a) HAADF-STEM images and EDS elemental maps of (b, blue) $\mathrm{Cu}$ and (c, red) Ga of product $\mathrm{NCs}$ obtained by reacting $\mathrm{Cu} \mathrm{u}_{2-x} \mathrm{~S}$ $\mathrm{NCs}$ with $\mathrm{GaCl}_{3}-\mathrm{TPP}$ at $100{ }^{\circ} \mathrm{C}$. Orange arrows indicate regions of low contrast (HAADF-STEM) coinciding with regions of low signal (EDS maps). 

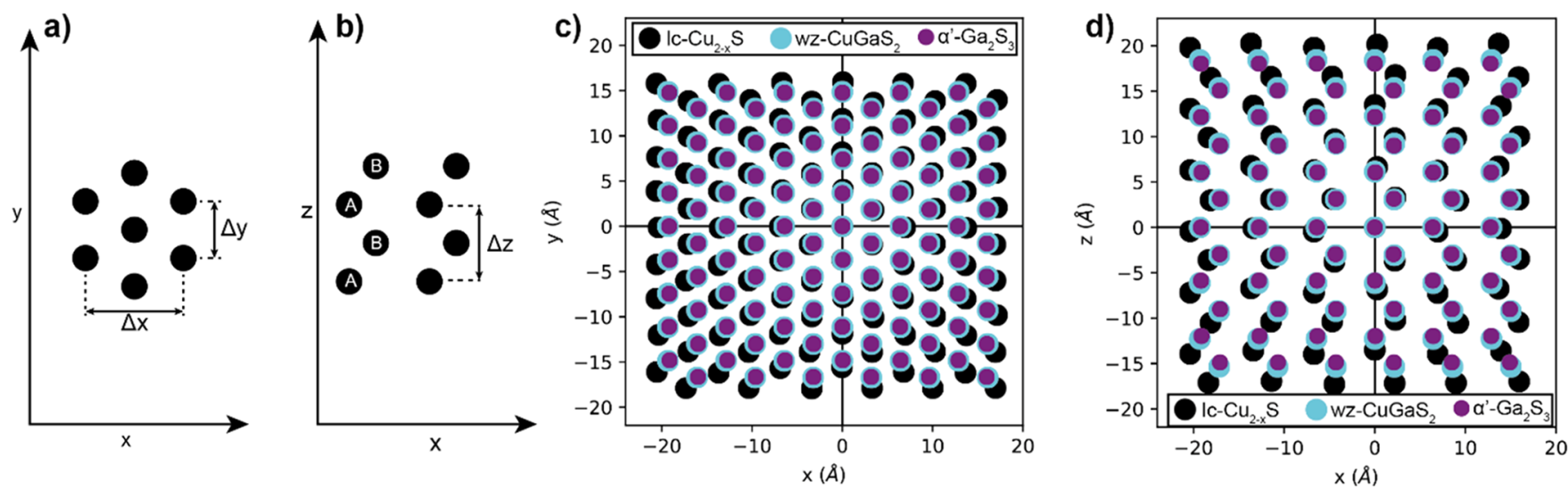

Figure 6. (a,b) Hexagonal close-packed structure viewed from two different orientations: (a) characteristic arrangement into hexagonally constructed layers, defined here as the $x, y$-plane, and (b) characteristic ...ABAB... stacking of these hexagonal layers, defined here as the $x, z$ plane. (c,d) Anion positions of (black) low-chalcocite $\mathrm{Cu}_{2-x} \mathrm{~S}$, (cyan) wurtzite $\mathrm{CuGaS}_{2}$, and (purple) $\alpha^{\prime}-\mathrm{Ga}_{2} \mathrm{~S}_{3}$ overlaid onto each other. (c) Hexagonal ordering in the $x, y$-plane and (d) ...ABAB... stacking in the $x, z$-plane. $\Delta x, \Delta y$, and $\Delta z$, denoted in (a,b), correspond to the lattice distances used to determine the lattice contractions mentioned in the main text. The $x, y, z$-directions correspond to the following crystallographic directions: (low-chalcocite $\left.\mathrm{Cu}_{2-x} \mathrm{~S}\right)[201],[010],[001] ;\left(\right.$ wurtzite $\left.\mathrm{CuGaS}_{2}\right)[1 \overline{10}],[110],[001] ;\left(\right.$ monoclinic $\left.\alpha^{\prime}-\mathrm{Ga}_{2} \mathrm{~S}_{3}\right)[010]$, $[100],[102]$. Anion coordinates were obtained from the crystal structures of low-chalcocite $\mathrm{Cu}_{2-x} \mathrm{~S}^{34}{ }^{34}$ wurtzite $\mathrm{CuGaS}_{2}{ }^{44}$ and monoclinic $\alpha^{\prime}$ $\mathrm{Ga}_{2} \mathrm{~S}_{3} .{ }^{46}$

(Supporting Information, Figure S3d,e). In the latter $\mathrm{NCs}, \mathrm{Cu}^{+}$ was exchanged for $\mathrm{Ga}^{3+}$ to a lesser extent; the presence of an LSPR absorption band thus indicates that these NCs remain cation-deficient, requiring excess holes for charge neutrality.

The intraparticle contrast observed in the NCs after reaction with $\mathrm{GaCl}_{3}-\mathrm{TPP}$ was studied with HAADF-STEM and EDS elemental mapping. In micrographs obtained using HAADFSTEM, the intraparticle contrast appears similar to that observed in TEM images (compare Figure 5a to Figure 4e). In the elemental maps, the regions of low contrast coincide with regions of low signal for both cations (Figure 5, indicated by orange arrows). As the $\mathrm{Cu}$ and $\mathrm{Ga}$ distributions correlate well (Figure $5 b, c)$, the intraparticle contrast is clearly not due to an inhomogeneous composition. Instead, it appears that the low contrast regions in HAADF-STEM and TEM images simply contain less material. Likely, surface erosion by $\mathrm{GaCl}_{3}$ is not completely suppressed when $\mathrm{GaCl}_{3}-\mathrm{TPP}$ is used as reactant, resulting in the formation of small cavities at the NC surface.

Similar to the previously reported conversion of lowchalcocite $\mathrm{Cu}_{2-x} \mathrm{~S}$ into wurtzite CIS NCs by $\mathrm{Cu}^{+}$for $\mathrm{In}^{3+}$ $\mathrm{CE},{ }^{16,18,33}$ the exchange of $\mathrm{Cu}^{+}$for $\mathrm{Ga}^{3+}$ in $\mathrm{Cu}_{2-x} \mathrm{~S}$ NCs using $\mathrm{GaCl}_{3}-\mathrm{DPP}$ or $\mathrm{GaCl}_{3}-\mathrm{TPP}$ as precursors is also partial and self-limited as CGS, rather than $\mathrm{Ga}_{2} \mathrm{~S}_{3}$, NCs are produced. In the case of the $\mathrm{Cu}^{+}$for $\mathrm{In}^{3+} \mathrm{CE}$ in $\mathrm{Cu}_{2-x} \mathrm{~S}$ NCs, the topotactic, partial, and self-limited character of the exchange was attributed to the high energy barrier associated with the conversion of the hexagonal close-packed anionic sublattice of the parent low-chalcocite $\mathrm{Cu}_{2-x} \mathrm{~S}$ NCs into the face-centered cubic sublattice of the spinel structure of $\operatorname{In}_{2} S_{3}$, which requires a substantial reorganization of the sulfide anions (by $58 \%$ of a S-S interatomic distance). ${ }^{16}$ In contrast, the hexagonal wurtzite structure of $\mathrm{CuInS}_{2}$ requires only minor rearrangements of the sulfide sublattice with respect to that of the template NCs (1.4 and 6.4\% contraction within and between the hexagonal $S^{2-}$ layers, respectively). ${ }^{16}$ The topotactic nature of the cation exchange in $\mathrm{Cu}_{2-x} \mathrm{~S}$ NCs has been recently exploited to achieve structure-selective conversion of $\mathrm{Cu}_{2-x} \mathrm{~S}$ $\mathrm{NC}$ templates into $\mathrm{ZnS}, \mathrm{CdS}$, and $\mathrm{CuInS}_{2}$, with hexagonal roxbyite $\mathrm{Cu}_{1.78} \mathrm{~S}$ and cubic digenite $\mathrm{Cu}_{1.8} \mathrm{~S}$ yielding product
NCs with the wurtzite and the zinc blende structures, respectively. ${ }^{45}$

In the present case, however, the structural differences between the possible products and the template NCs are less pronounced because low-chalcocite $\mathrm{Cu}_{2-x} \mathrm{~S}$, wurtzite $\mathrm{CuGaS}_{2}$, and the stable form of bulk $\mathrm{Ga}_{2} \mathrm{~S}_{3}$, monoclinic $\alpha^{\prime}-\mathrm{Ga}_{2} \mathrm{~S}_{3}$, all have a hexagonal close-packed sulfide sublattice, ${ }^{34,44,46}$ with hexagonally structured layers stacked in an ...ABAB... fashion (Figure 6a,b). However, we observe that, in all three dimensions, the wurtzite $\mathrm{CuGaS}_{2}$ structure exhibits a significant lattice contraction compared to that of lowchalcocite $\mathrm{Cu}_{2-x} \mathrm{~S}$ (Figure 6c,d). These contractions are 5.6, 5.7 , and $9.5 \%$ in $x, y$, and $z$, respectively. On the other hand, the anion positions of wurtzite $\mathrm{CuGaS}_{2}$ and $\alpha^{\prime}-\mathrm{Ga}_{2} \mathrm{~S}_{3}$ are very similar: transforming the former into the latter, the lattice has to contract by only $0.6,0.5$, and $2.5 \%$ in $x, y$, and $z$, respectively (the definition of $x, y$, and $z$ directions in terms of crystallographic directions are provided in the caption of Figure 6). It is thus clear that, based on the bulk crystal structure parameters, the sulfide sublattice of the template lowchalcocite $\mathrm{Cu}_{2-x} \mathrm{~S}$ would have to undergo similar degrees of reconstruction, regardless of whether the cation exchange would be partial, yielding wurtzite $\mathrm{CuGaS}_{2}$, or complete, yielding $\alpha^{\prime}-\mathrm{Ga}_{2} \mathrm{~S}_{3}$. However, we note that the product wurtzite CGS NCs (with $\mathrm{Cu} / \mathrm{Ga}$ ratios ranging from $1: 1.48$ to $1: 0.62$ ) obtained in our work exhibit a larger lattice constant than the wurtzite $\mathrm{CuGaS}_{2}$ reference (Figure 4h,i), indicating that the degree of contraction was smaller than expected based on the bulk lattice parameters, and therefore, that the product CGS NCs are under tensile strain. This suggests that the mild reaction conditions used in our work do not allow the anion sublattice to undergo full reconstruction in order to relax the strain induced by the CE.

Recently, lattice strain was shown to play an important role in the conversion of djurleite $\mathrm{Cu}_{2-x} \mathrm{~S}$ nanorods (NRs) into $\mathrm{Cu}_{2-x} \mathrm{~S} / \mathrm{CGS}$ hetero-NRs by partial $\mathrm{Cu}^{+}$for $\mathrm{Ga}^{3+} \mathrm{CE}^{30}$ Shim and co-workers showed that lattice strain prevented the homogeneous conversion of $\mathrm{Cu}_{2-x} \mathrm{~S}$ NRs $(\sim 170 \mathrm{~nm}$ long, 20 $\mathrm{nm}$ diameter) into CGS NRs, resulting instead in hetero-NRs containing one or multiple wurtzite CGS domains. ${ }^{30}$ The 
authors argued that the strain induced by the lattice mismatch between the parent djurleite $\mathrm{Cu}_{2-x} \mathrm{~S}$ phase and the product wurtzite CGS phase would make $\mathrm{Ga}^{3+}$ diffusion into $\mathrm{Cu}_{2-x} \mathrm{~S}$ unfavorable, thereby limiting the extent of the $\mathrm{CE}$ reaction and leading to wurtzite-djurleite superlattice formation as a way to minimize the resulting strain. However, we note that in the present work $\mathrm{Cu}_{2-x} \mathrm{~S}$ NCs were successfully converted into homogeneous CGS NCs, despite the tensile strain resulting from insufficient contraction to the lattice parameters of fully relaxed bulk $\mathrm{CuGaS}_{2}$. This difference can be attributed to the fact that the NCs used here are much smaller than those used by Shim and co-workers (viz. $12 \mathrm{~nm}$ diameter $v s \sim 170 \mathrm{~nm}$ long, $20 \mathrm{~nm}$ diameter rods). The smaller volume of the template NCs used in our work favors conversion to homogeneous CGS NCs because smaller NCs can more easily accommodate lattice strain. This also offers a possible explanation for the self-limiting character of the $\mathrm{Cu}^{+}$for $\mathrm{Ga}^{3+}$ exchange in $\mathrm{Cu}_{2-x} \mathrm{~S}$ NC templates: the $\alpha^{\prime}-\mathrm{Ga}_{2} \mathrm{~S}_{3}$ structure is probably unable to accommodate as much tensile strain as wurtzite CGS, preventing full CE.

Density Functional Theory Calculations. To corroborate our assumption of weaker $\mathrm{Ga}-\mathrm{P}$ bond strengths in $\mathrm{GaCl}_{3}-\mathrm{DPP}$ and $\mathrm{GaCl}_{3}-\mathrm{TPP}$ with respect to $\mathrm{GaCl}_{3}-\mathrm{TOP}$, we conducted DFT calculations at the B3LYP/6-311+G(d,p);Ga:SDD level to estimate both the ground-state geometry of the complexes and the $\mathrm{Ga}-\mathrm{P}$ bond enthalpy. In the DFT calculations, we modeled TOP as triethylphosphine to avoid an extensive conformational search due to the many degrees of freedom of the long alkyl chains. We expect that only the first few $\mathrm{CH}_{2}$ groups of TOP significantly influence the $\mathrm{Ga}-\mathrm{P}$ bond, making $\mathrm{PEt}_{3}$ an acceptable surrogate for TOP. To verify whether the outcome of these calculations is physically reasonable, we compare calculated geometries to experimental structures obtained from $\mathrm{X}$-ray crystallography. We include an additional complex $\left(\mathrm{GaCl}_{3}-\mathrm{PPh}_{3}\right)$, as, to the best of our knowledge, the structures of $\mathrm{GaCl}_{3}-\mathrm{DPP}$ and $\mathrm{GaCl}_{3}$-TPP have not been resolved experimentally. The results of the DFT calculations ( $\mathrm{Ga}-\mathrm{P}$ bond lengths and dissociation enthalpies) and the experimentally determined $\mathrm{Ga}-\mathrm{P}$ bond lengths are shown in Table 1 . The Ga-P bond

Table 1. DFT-Calculated (B3LYP/6-311+G(d,p);Ga:SDD) and Experimental Ga-P Bond Lengths and DFT-Calculated Dissociation Enthalpies of $\mathrm{GaCl}_{3}-\mathrm{PEt}_{3}, \mathrm{GaCl}_{3}-\mathrm{PPh}_{3}$, $\mathrm{GaCl}_{3}-\mathrm{DPP}$, and $\mathrm{GaCl}_{3}-\mathrm{TPP}$

$\begin{array}{cclc}\text { complex } & \begin{array}{c}\mathrm{Ga}-\mathrm{P} \text { bond } \\ \text { length }(\AA), \\ \text { calculated }\end{array} & \begin{array}{c}\mathrm{Ga}-\mathrm{P} \text { bond } \\ \text { length }(\AA), \\ \text { experimental }\end{array} & \begin{array}{c}\text { dissociation } \\ \text { enthalpy }(\mathrm{kcal} / \mathrm{mol}), \\ \text { calculated }\end{array} \\ \mathrm{GaCl}_{3}-\mathrm{PEt}_{3} & 2.453 & 2.353^{47} & 31.2 \\ \mathrm{GaCl}_{3}-\mathrm{PPh}_{3} & 2.487 & 2.372^{48} & 27.2 \\ \mathrm{GaCl}_{3}-\mathrm{DPP} & 2.498 & \text { not available } & 23.0 \\ \mathrm{GaCl}_{3}-\mathrm{TPP} & 2.540 & \text { not available } & 14.7\end{array}$

lengths determined by DFT deviate from the experimental ones by only $4-5 \%$. Moreover, the DFT results reproduce the experimental trend in $\mathrm{Ga}-\mathrm{P}$ bond length from $\mathrm{GaCl}_{3}-\mathrm{PEt}_{3}$ to $\mathrm{GaCl}_{3}-\mathrm{PPh}_{3}$. Thus, although the absolute values obtained from the DFT calculations are 4-5\% longer than the experimental ones, the trends in the DFT results are reliable. We observe that, with increasing electron-withdrawing nature of the side groups on the phosphine ligand, the $\mathrm{Ga}-\mathrm{P}$ bond length $L$ increases (viz., $L_{\mathrm{GaCl}_{3}-\mathrm{TOP}}<L_{\mathrm{GaCl}_{3}-\mathrm{DPP}}<L_{\mathrm{GaCl}_{3}-\mathrm{TPP}}$ ).
The dissociation enthalpy follows the reverse trend. These results show that, indeed, the $\mathrm{Ga}-\mathrm{P}$ bonds in $\mathrm{GaCl}_{3}-\mathrm{DPP}$ and $\mathrm{GaCl}_{3}$-TPP are weaker than those in $\mathrm{GaCl}_{3}-\mathrm{TOP}$.

Mechanism for the $\mathrm{Cu}^{+}$for $\mathrm{Ga}^{3+}$ Exchange in $\mathrm{Cu}_{2-x} \mathrm{~S}$ NCs. Nanoscale CE reactions consist of a number of linked elementary kinetic steps: ${ }^{5,6,8,12}$ (i) extraction of the host cations from the NC surface, (ii) incorporation of guest cations at the NC surface, (iii) solid-state diffusion of the guest cations into the $\mathrm{NC}$, and (iv) solid-state diffusion of the native cations to the NC surface. The thermodynamic driving force for the reaction is determined by the energy balance of the overall reaction. ${ }^{5,6,8}$ However, the energy input or output involved in each step is important as all steps are kinetically linked and must proceed in a concerted manner. Therefore, the outcome of nanoscale CE reactions (i.e., extent of the exchange, homogeneous or heterostructured nanocrystals, etc.) is dictated by the kinetic balance between a number of competing processes taking place in solution, at the NC surface and within the NC.

Aliovalent CE reactions are inherently more complex than isovalent ones as preservation of charge balance is in this case kinetically more challenging because a different number of host and guest cations must be exchanged to keep charge neutrality (e.g., three $\mathrm{Cu}^{+}$cations must be extracted to allow the incorporation of one $\mathrm{In}^{3+}$ or $\mathrm{Ga}^{3+}$ cation). Aliovalent $\mathrm{CE}$ involving $\mathrm{Cu}^{+}$has been extensively investigated because the small charge and high solid-state diffusion rates of $\mathrm{Cu}^{+}$ions make both their incorporation into and extraction from NCs facile and fast. This makes copper chalcogenide NCs attractive not only as templates for other binary, multinary, or heteroNCs that cannot be easily obtained by direct routes (e.g., $\mathrm{CuInS}_{2},{ }^{16,28,30,33,37,45} \mathrm{CuInSe}_{2},{ }^{8,49,50} \mathrm{Cu}_{4} \mathrm{SnS}_{4}{ }^{19,51} \mathrm{Cu}_{2-x} \mathrm{Se} /$ $\mathrm{ZnSe}{ }^{52} \mathrm{ZnS} / \mathrm{Cu}_{1.8} \mathrm{~S}^{28,53}$ etc.) but also as intermediates in sequential $\mathrm{CE}$ reactions, making it possible to synthesize NCs and hetero-NCs that would otherwise remain inaccessible (e.g., $\mathrm{PbS}$ NRs from CdS NRs by $\mathrm{Cd}^{2+}$ for $\mathrm{Cu}^{+}$followed by $\mathrm{Cu}^{+}$for $\mathrm{Pb}^{2+} \mathrm{CE}{ }^{5}$ wurtzite $\mathrm{ZnSe} / \mathrm{ZnS}$ and $\mathrm{CuInSe}_{2} / \mathrm{CuInS}_{2}$ core/shell $\mathrm{NRs}$ from $\mathrm{CdSe} / \mathrm{CdS}$ core/shell NRs ${ }^{18,54}$ ). As a result of this extensive research, the thermodynamics and kinetics of aliovalent $\mathrm{CE}$ reactions involving $\mathrm{Cu}^{+}$are reasonably wellunderstood and known to depend on many variables: presence of $\mathrm{Cu}$-extracting ligands in solution, ${ }^{5,6,8}$ leaving ability of the ligands bound to the incoming guest $\mathrm{M}^{n+}$ cation, ${ }^{37}$ concentration of $\mathrm{Cu}^{+}$vacancies, ${ }^{52,55}$ valence and diffusion rate of the incoming guest $\mathrm{M}^{n+}$ cation, ${ }^{8,28,30}$ crystal structure of the template $\mathrm{Cu}_{2-x} \mathrm{~S} \mathrm{NCs}$, ${ }^{8,45}$ and miscibility of the parent and product phases. As we will discuss below, the results presented above unravel one more crucial parameter governing the kinetics of $\mathrm{CE}$ reactions: the activated complex that must form at the surface of the template $\mathrm{NC}$ when a direct place exchange reaction is used (i.e., when the Cu-extracting ligand is bound to the guest heterocation).

As previously demonstrated by Buhro and co-workers, ${ }^{37}$ the aliovalent $\mathrm{Cu}^{+}$for $\mathrm{In}^{3+}$ exchange in $\mathrm{Cu}_{2-x} \mathrm{~S}$ NCs is in the reaction-limited regime. The incorporation of $\mathrm{In}^{3+}$ is preceded by the adsorption of the $\operatorname{InX}_{3}$ precursor on the NC surface. The displacement of the $\mathrm{X}^{-}$ligand is proposed to occur by nucleophilic attack of lattice $S^{2-}$ ions on the adsorbed $\operatorname{In} X_{3}$ precursor. ${ }^{37}$ The height of the energy barrier for this reaction is given by the leaving-group ability of the $\mathrm{X}^{-}$ligand. ${ }^{37}$ We add that when a direct place exchange reaction is promoted by using a TOP- $\mathrm{InCl}_{3}$ complex, the energy barrier is lowered by the formation of an incipient bond between the $\mathrm{P}$ donor group 

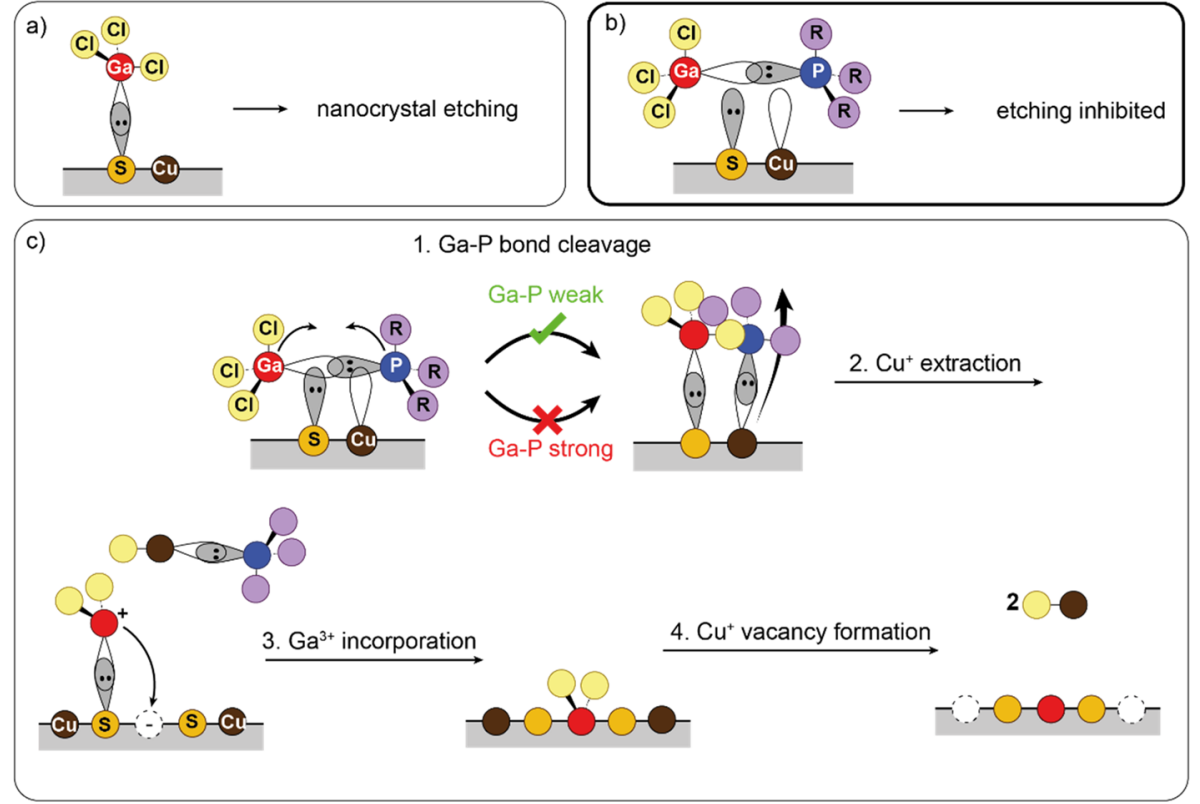

Figure 7. Schematic depiction of the $\mathrm{Cu}^{+}$for $\mathrm{Ga}^{3+}$ cation exchange reaction in $\mathrm{Cu}_{2-x} \mathrm{~S}$ nanocrystals. (a) Free $\mathrm{GaCl}_{3}$ reacts as a Lewis acid, extracting $\mathrm{S}^{2-}$, leading to etching of the nanocrystals. (b) Extraction of $\mathrm{S}^{2-}$ is inhibited when $\mathrm{GaCl}_{3}$ is complexed with a phosphine ligand. (c) Successful cation exchange involves four steps: (i) cleavage of the $\mathrm{Ga}-\mathrm{P}$ bond at the $\mathrm{Cu}_{2-x} \mathrm{~S}$ nanocrystal surface, at which point $\mathrm{Ga}-\mathrm{S}$ and $\mathrm{P}-\mathrm{Cu}$ bonds are made simultaneously; (ii) extraction of $\mathrm{Cu}^{+}$by the phosphine; (iii) subsequent incorporation of $\mathrm{Ga}^{3+}$ into the nanocrystal; and (iv) reaction of remaining $\mathrm{Cl}^{-}$with $\mathrm{Cu}^{+}$, extracting two additional $\mathrm{Cu}^{+}$ions, completing the exchange.

and a $\mathrm{Cu}^{+}$ion in the vicinity of the $\mathrm{S}^{2-}$ ion responsible for the nucleophilic attack on the $\mathrm{In}-\mathrm{Cl}$ bond. This makes the reaction rates faster and allows for a direct place exchange between the incoming $\mathrm{In}^{3+}$ guest cation and one outgoing $\mathrm{Cu}^{+}$ cation, while facilitating extraction of two additional $\mathrm{Cu}^{+}$ions as neutral $\mathrm{CuCl}$ units. However, the formation of such an activated complex imposes constraints on the orientation of the binding TOP $-\mathrm{InCl}_{3}$ with respect to the surface $\mathrm{Cu}^{+}$and $\mathrm{S}^{2-}$. Nevertheless, in the case of $\mathrm{Cu}^{+}$for $\mathrm{In}^{3+} \mathrm{CE}$, these constraints are not very strict because the activated complex can follow only two possible reaction pathways: CE or desorption without reaction, in which case it may bind again in the proper orientation later.

In the case of $\mathrm{Cu}^{+}$for $\mathrm{Ga}^{3+} \mathrm{CE}$, the constraints imposed on the activated complex are more severe because $\mathrm{GaCl}_{3}$ is a much stronger Lewis acid than $\mathrm{InCl}_{3}$, therefore being capable of extracting lattice $\mathrm{S}^{2-}$ from the template $\mathrm{Cu}_{2-x} \mathrm{~S}$ NCs ( $\mathrm{Ga}-\mathrm{S}$ $=393 \mathrm{~kJ} / \mathrm{mol}, \mathrm{In}-\mathrm{S}=313-316 \mathrm{~kJ} / \mathrm{mol}),{ }^{56}$ leading to etching rather than $\mathrm{CE}$ (Figure $7 \mathrm{a}$ ), as demonstrated above (Figures 2 and 3). Complexation of $\mathrm{GaCl}_{3}$ with TOP suppresses the NC etching but does not lead to $\mathrm{CE}$. This demonstrates that the activated complex formed upon adsorption of $\mathrm{GaCl}_{3}-\mathrm{TOP}$ on the NC surface effectively weakens the interaction between $\mathrm{Ga}$ and the lattice $S^{2-}$ and also prevents interaction between the $P$ donor head and the $\mathrm{Cu}^{+}$ions (Figure $7 \mathrm{~b}$ ). In contrast, both $\mathrm{GaCl}_{3}-\mathrm{TPP}$ and $\mathrm{GaCl}_{3}-\mathrm{DPP}$ result in successful $\mathrm{Cu}^{+}$for $\mathrm{Ga}^{3+}$ CE. All three ligands (TOP, TPP, DPP) are bound to $\mathrm{GaCl}_{3}$ through the lone pair on the phosphorus atom and an empty $\mathrm{sp}^{3}$ orbital of gallium. ${ }^{48,57,58}$ To extract $\mathrm{Cu}^{+}$, the phosphine acts as Lewis base and binds to $\mathrm{Cu}^{+}$through the same lone pair. In order for the phosphine to bind to $\mathrm{Cu}^{+}$, while still preventing etching by attack of the $\mathrm{Ga}^{3+}$ to lattice $\mathrm{S}^{2-}$ ions, the activated complex at the NC surface (Figure $7 \mathrm{c}$ ) must be such that the $\mathrm{Cu}-\mathrm{P}$ bond formation and the $\mathrm{Ga}-\mathrm{P}$ bond breaking occur simultaneously (Figure 7c, steps 1-3) and are followed by the immediate place exchange between $\mathrm{Cu}^{+}$and $\mathrm{Ga}^{3+}$. We attribute the higher CE reactivities of the $\mathrm{GaCl}_{3}-\mathrm{TPP}$ and $\mathrm{GaCl}_{3}-\mathrm{DPP}$ to a more favorable geometry of the activated complex formed upon their adsorption on the surface of the template $\mathrm{Cu}_{2-x} \mathrm{~S}$ $\mathrm{NCs}$, as well as a weaker $\mathrm{Ga}-\mathrm{P}$ bond compared to $\mathrm{GaCl}_{3}-$ TOP. In $\mathrm{GaCl}_{3}-\mathrm{TPP}$ and $\mathrm{GaCl}_{3}-\mathrm{DPP}$, the $\mathrm{Ga}-\mathrm{P}$ bond is weaker than that in $\mathrm{GaCl}_{3}$-TOP (see Table 1), fulfilling the conditions for a fast place exchange between $\mathrm{Ga}^{3+}$ and $\mathrm{Cu}^{+}$, while still making the competing reaction between $\mathrm{GaCl}_{3}$ and the lattice $\mathrm{S}^{2-}$ ions less likely (Figure $7 \mathrm{c}$, steps $1-3$ ). We note that the $\mathrm{Cu}^{+}$for $\mathrm{Ga}^{3+}$ place exchange is thermodynamically favored as it results in the formation of two new bonds that are stronger than the initial ones (viz., the $\mathrm{Cu}-\mathrm{P}$ bond in the $\mathrm{Cu}-$ phosphine Lewis acid-base adduct, which is favored because $\mathrm{Cu}^{+}$is a much softer Lewis acid than $\mathrm{Ga}^{3+}, \eta=6.28$ and $17 \mathrm{eV}$, respectively, ${ }^{32}$ and the $\mathrm{Ga}-\mathrm{S}$ bond, which has a bond strength of $393 \mathrm{~kJ} / \mathrm{mol}$ while the enthalpy of formation of $\mathrm{Cu}_{2} \mathrm{~S}$ is only $-79.5 \mathrm{~kJ} / \mathrm{mol}^{59}$ ). Nevertheless, some degree of etching still occurs as the NCs reacted with $\mathrm{GaCl}_{3}-\mathrm{TPP}$ and $\mathrm{GaCl}_{3}-\mathrm{DPP}$ are smaller than the template NCs (viz., $10.8 \pm 1.0,11.1 \pm 1.1$, and $12.3 \pm 1.0 \mathrm{~nm}$, respectively, Supporting Information, Figure S1). The observed shrinkage (12.2 and 9.76\%, respectively) is too large to be attributed to a decrease in unit cell volume alone (see discussion on crystal lattice contraction above). The difference in reactivity between InCl $\mathrm{Cl}_{3}-\mathrm{TOP}$ and $\mathrm{GaCl}_{3}-\mathrm{TOP}$ as $\mathrm{CE}$ reactants may be due to the fact that $\mathrm{In}^{3+}$ exhibits three-, four-, five-, and sixcoordination, whereas $\mathrm{Ga}^{3+}$ is limited to three- and fourcoordination. ${ }^{57} \mathrm{InCl}_{3}$-TOP has thus more degrees of freedom to rearrange itself at the nanocrystal surface to form the $\mathrm{Cu}_{2-x} \mathrm{~S}-\mathrm{InCl}_{3}$-TOP activated complex, whereas $\mathrm{GaCl}_{3}$-TOP does not, making the formation of the $\mathrm{Cu}_{2-x} \mathrm{~S}-\mathrm{GaCl}_{3}-\mathrm{TOP}$ activated complex subjected to more stringent orientational constraints and therefore less likely. 
As mentioned above, the steric demands of all three phosphines used in the present work are essentially the same (viz., $128^{\circ}$ for DPP and TPP, $132^{\circ}$ for TOP), ${ }^{41}$ and therefore, steric effects are not expected to play a significant role in the outcome of the cation exchange reactions. However, Tolman cone angles are just a first approximation as they do not take into account the effect of different $\mathrm{M}-\mathrm{P}$ bond lengths, different metal centers, and the overall interaction with other ligands coordinated to the same metal center. ${ }^{43,60,61}$ Therefore, actual cone angles obtained from X-ray structural data (the socalled solid cone angles) typically deviate from the Tolman cone angles, varying over a wide range depending on the nature of the metal center and bond length (shorter bonds result in larger cone angles). ${ }^{60}$ For example, the solid cone angles determined for triphenylphosphine complexes range from 129 to $168^{\circ},{ }^{61}$ whereas the Tolman cone angle of triphenylphosphine is $145^{\circ} .^{41,43}$ In the case of Ni complexes, a slightly larger solid cone angle has been reported for TPP with respect to DPP complexes (135 and $124^{\circ}$, respectively), ${ }^{43}$ consistent with the bulkier nature of the former (containing three phenyl groups) with respect to the latter (which contains only two phenyl groups). If the impact of steric effects on the outcome of the cation exchange reactions were significant, one would expect a difference between the reactivity of the complexes using TPP and DPP as ligands, in contrast with our experimental data, which show that $\mathrm{GaCl}_{3}-\mathrm{TPP}$ and $\mathrm{GaCl}_{3}-$ DPP have similar reactivities. This implies that the kinetics of the cation exchange reactions studied in our work are primarily dictated by the electronic properties of the phosphine ligands used, which determine the $\mathrm{Ga}-\mathrm{P}$ bond strength of the resulting Lewis acid-base adduct complexes with $\mathrm{GaCl}_{3}$ and the geometry of the activated $\mathrm{Cu}_{2-x} \mathrm{~S}-\mathrm{GaCl}_{3}-\mathrm{L}$ complex that forms at the surface of the $\mathrm{Cu}_{2-x} \mathrm{~S} \mathrm{NC}$ at the onset of the cation exchange reaction. After the place exchange between the outgoing $\mathrm{Cu}^{+}$and the incoming $\mathrm{Ga}^{3+}$ cations has taken place, the two chlorides still bound to the incorporated $\mathrm{Ga}^{3+}$ cation will react with two neighboring $\mathrm{Cu}^{+}$cations, extracting them from the $\mathrm{NC}$ surface as neutral $\mathrm{CuCl}$ units, which are highly soluble in the apolar reaction medium used in our experiments (Figure 7c, step 4). This likely increases the thermodynamic driving force of the overall $\mathrm{CE}$ reaction both entropically and enthalpically as two more chemical species are released in solution and solvated. ${ }^{5,6,8}$ The two $\mathrm{Cu}^{+}$vacancies left will further promote the $\mathrm{CE}$ reaction by allowing more $\mathrm{Cu}^{+}$cations to diffuse to the surface, while allowing the incorporated $\mathrm{Ga}^{3+}$ guest cation to diffuse inward. As previously shown for $\mathrm{CE}$ reactions in copper chalcogenide NCs, the CE rates increase with increasing concentration of $\mathrm{Cu}^{+}$vacancies. ${ }^{52,62}$

$\mathrm{Cu}^{+}$for $\mathrm{Ga}^{3+}$ Exchange in Luminescent CulnS $\mathrm{SCs}_{2}$. To illustrate the general applicability of the findings presented above, we used $\mathrm{GaCl}_{3}-\mathrm{DPP}$ to convert luminescent $\mathrm{CuInS}_{2}$ (CIS) NCs into (Cu,In,Ga) $S_{2}$ (CIGS) NCs with much brighter photoluminescence (see Methods for details). The parent CIS NCs have an indium-rich composition with a $\mathrm{Cu}$ / In ratio of $0.68 \pm 0.008: 1$. EDS analysis of the product NCs gives a $\mathrm{Cu} / \mathrm{Ga} / \mathrm{In}$ ratio of $0.20 \pm 0.001: 0.16 \pm 0.001: 1$, indicating that $\mathrm{Cu}^{+}$ions are exchanged for $\mathrm{Ga}^{3+}$. These cation ratios imply that the charge balance is preserved through the $\mathrm{CE}$ reaction, as the relative concentration of $\mathrm{Ga}$ ions multiplied by their charge of +3 exactly corresponds to the decrease in $\mathrm{Cu}$ concentration (with charge $+1 ; 0.16 \times 3=0.48 ; 0.68-0.20=$ $0.48)$. Interestingly, the size $(\sim 5.5 \mathrm{~nm})$ and pyramidal shape of the CIS NCs are preserved in the product CIGS NCs (see
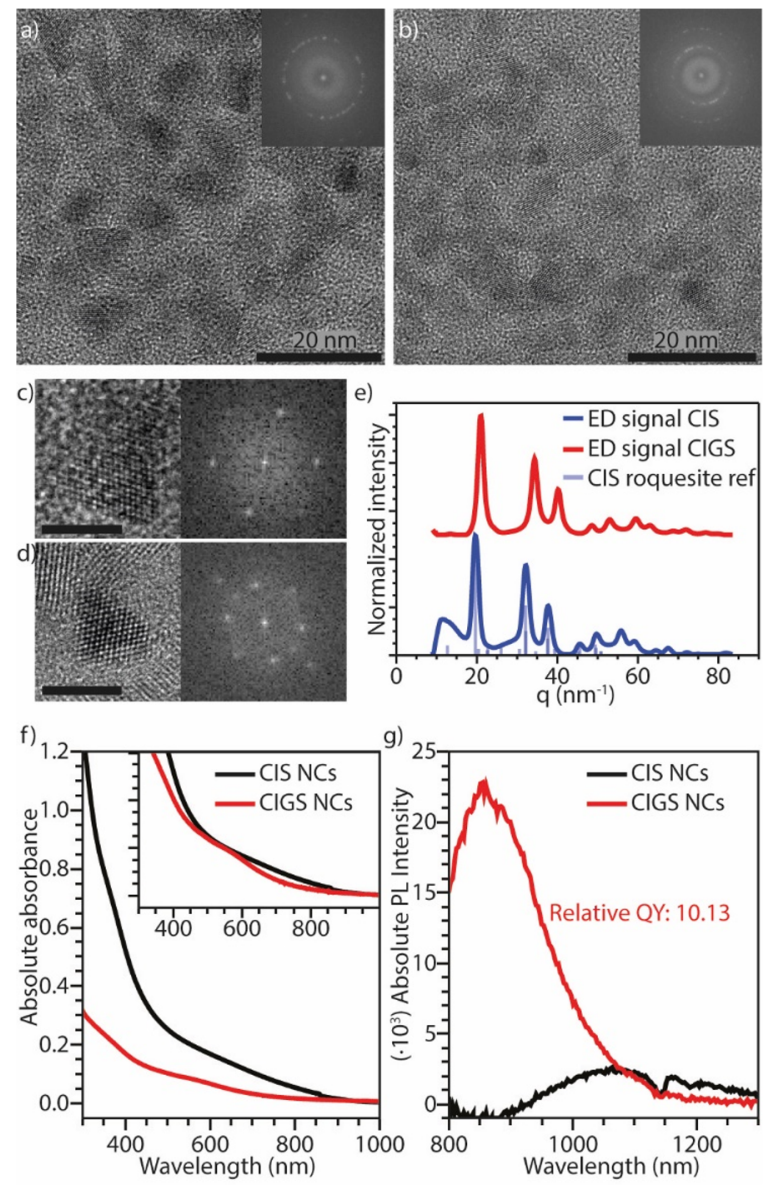

Figure 8. $\mathrm{Cu}^{+}$for $\mathrm{Ga}^{3+}$ cation exchange in luminescent CIS NCs. (a) High-resolution TEM image of the parent CIS NCs. The inset shows the FFT of the image. (b) High-resolution TEM image of the product CIGS NCs after reaction; the inset shows the FFT of the image. (c,d) Enlarged TEM image of single NCs before (c) and after (d) the $\mathrm{Ga}^{3+}$ for $\mathrm{Cu}^{+} \mathrm{CE}$ reaction, with the corresponding FFTs. Both scale bars correspond to $5 \mathrm{~nm}$. (e) Azimuthally integrated ED patterns of the parent CIS NCs and product CIGS NCs, and bulk roquesite CIS X-ray diffraction reference pattern (JPCDS PDF-card 00-047-1372). (f) Absorption and (g) PL spectra of the parent CIS NCs and product CIGS NCs. The inset in (f) shows the normalized absorption spectra. The PL quantum yield of the product CIGS NCs is at least 10 times higher than that of the parent CIS NCs. The dip in the PL spectrum around 1150 $\mathrm{nm}$ is caused by absorption of emitted light by toluene, which was used as solvent.

Figure $8 \mathrm{a}, \mathrm{d}$ ), despite the removal of a significant amount of cations from the NC. Fast Fourier transform (FFT) analysis of the high-resolution TEM images allows determination of the lattice spacings, being $0.18,0.21$, and $0.34 \mathrm{~nm}$ before and after the reaction (i.e., they are not significantly changed by the $\mathrm{CE}$ reaction). However, analysis of the ED patterns shows a shift to higher $q$ values (Figure 8e), indicating a small contraction of the unit cell. This contraction is consistent with the exchange of the relatively large $\mathrm{Cu}^{+}$for the relatively small $\mathrm{Ga}^{3+}\left(r_{\mathrm{Cu}^{+}}{ }^{+}=\right.$ $\left.60 \mathrm{pm}, r_{\mathrm{Ga}^{3+}}=47 \mathrm{pm}\right) .^{31}$

The optical properties of the template CIS NCs and the product Ga-containing (CIGS) NCs are shown in Figure 8f,g. Both the absorption (Figure $8 \mathrm{f}$ ) and photoluminescence (PL, Figure $8 \mathrm{~g}$ ) spectra show a blue shift after the CE reaction, indicating a widening of the band gap. This can be attributed to either an increase in quantum confinement due to a smaller 
effective CIS core size, ${ }^{2,33}$ in case a CIS/CIGS core/shell NC is formed, or by the intrinsic increase in band gap, ${ }^{63,64}$ in case a homogeneous CIGS alloy is formed, as the band gap of bulk $\mathrm{CuGaS}_{2}$ is larger than that of $\mathrm{CuInS}_{2}(2.50$ and $1.55 \mathrm{eV}$, respectively). ${ }^{1-3}$ Our results, however, do not allow a distinction between the two cases to be made. The PL quantum yield (QY) of the product CIGS NCs increases by 1 order of magnitude in comparison to that of the parent CIS NCs (Figure 8g). Such an increase in PLQY could originate from a strong enhancement of the radiative recombination rates, from elimination of nonradiative recombination pathways, or from a combination of both. Considering that similar PLQY enhancements have been previously observed upon shelling of CIS NCs with both $\mathrm{ZnS}$ and CdS, and attributed to passivation of nonradiative recombination centers at the surface, ${ }^{1,65-67}$ it is likely that the higher PLQY of the CIGS NCs obtained by cation exchange is also due to improved surface passivation. It is interesting to note that PL of CIGS NCs is generally not reported, ${ }^{26,68}$ suggesting that the exciton recombination in these materials tends to be dominated by nonradiative decay pathways, in striking contrast to the $\mathrm{Cu}$ poor) CIGS NCs prepared in our work by postsynthetic $\mathrm{Cu}^{+}$ for $\mathrm{Ga}^{3+}$ cation exchange in CIS NCs. The scarce literature on the PL of CIGS NCs makes it difficult to unambiguously identify the radiative recombination mechanism in these materials. However, their large global Stokes shift and broad PL peak suggest that, similar to CIS and other I-III-VI 2 NCs, the PL in these nanomaterials most likely originates from the radiative recombination of a delocalized conduction band electron with a hole localized at a $\mathrm{Cu}(\mathrm{I})$ ion. ${ }^{69}$ Time-resolved spectroscopic measurements could provide additional insights into the origin of the radiative recombination in these nanomaterials but are beyond the scope of the present work. It should be noted that the PL of these $\mathrm{Pb}$ - and Cd-free NCs is centered in the NIR biological window. ${ }^{65}$ This, in combination with their high PLQY, makes them promising candidates for bioimaging applications. Most importantly, the results discussed above show that the $\mathrm{CE}$ mechanism proposed in the present work is widely applicable.

\section{CONCLUSIONS}

Our work shows the importance of reactant chemistry in aliovalent cation exchange reactions in $\mathrm{Cu}_{2-x} \mathrm{~S}$ nanocrystals. Noncomplexed $\mathrm{GaCl}_{3}$ reacts as Lewis acid, extracting $\mathrm{S}^{2-}$ from the nanocrystals, thereby etching them. Etching is inhibited when $\mathrm{GaCl}_{3}$ is bound to a phosphine ligand in a $\mathrm{GaCl}_{3}-\mathrm{L}$ complex $(\mathrm{L}=$ trioctylphosphine, triphenylphosphite, and diphenylphosphine). $\mathrm{GaCl}_{3}$-TOP was found to be unreactive, whereas $\mathrm{GaCl}_{3}-\mathrm{TPP}$ and $\mathrm{GaCl}_{3}-\mathrm{DPP}$ lead to successful exchange of $\mathrm{Cu}^{+}$for $\mathrm{Ga}^{3+}$, converting the parent $\mathrm{Cu}_{2-x} \mathrm{~S}$ nanocrystals into $\mathrm{CuGaS}_{2}$ nanocrystals. This is rationalized by considering that the activated $\mathrm{Cu}_{2-x} \mathrm{~S}-\mathrm{GaCl}_{3}-\mathrm{L}$ complex that forms at the surface of the nanocrystal upon adsorption of the $\mathrm{GaCl}_{3}-\mathrm{L}$ complex must allow for simultaneous $\mathrm{Ga}^{3+}$ insertion and $\mathrm{Cu}^{+}$extraction, while preventing $\mathrm{S}^{2-}$ extraction. This requirement is only fulfilled by activated complexes in which the $\mathrm{Ga}-\mathrm{P}$ bond is sufficiently weak. DFT calculations show that the $\mathrm{Ga}-\mathrm{P}$ bond strength decreases with increasing electron-withdrawing nature of the side groups of the phosphine ligand. Our findings highlight several factors (viz., Lewis acidity, influence of ligand electronic properties on reactivity) which need be taken into account when designing cation exchange protocols. Finally, we showed that the mechanism proposed here is generally applicable by using $\mathrm{GaCl}_{3}-\mathrm{DPP}$ to convert $\mathrm{CuInS}_{2}$ nanocrystals into $\mathrm{Cu}$-poor $(\mathrm{Cu}, \mathrm{Ga}, \mathrm{In}) \mathrm{S}_{2}$ nanocrystals with an increased photoluminescence quantum yield in the NIR spectral window.

\section{METHODS}

Materials. Copper(II) sulfate pentahydrate $\left(\mathrm{CuSO}_{4} \cdot 5 \mathrm{H}_{2} \mathrm{O}\right.$, 99.995\%), oleic acid (OA, tech., 90\%), 1-dodecanethiol (DDT, $\geq 98 \%$ ), oleylamine (tech., $70 \%$ ), gallium(III) chloride $\left(\mathrm{GaCl}_{3}\right.$, anhydrous, beads), trioctylphosphine (90\%), diphenylphosphine (98\%), triphenylphosphite (97\%), indium(III) acetate (In(Ac), 99.99\%), copper(I) iodide (CuI, 98\%), anhydrous methanol, anhydrous butanol, and anhydrous toluene were all purchased from Sigma-Aldrich and used as supplied, except for OA and OLAM, which were degassed prior to use.

Synthesis of $\mathrm{Cu}_{2-x} \mathrm{~S}$ Bifrustum Nanocrystals. $\mathrm{Cu}_{2-x} \mathrm{~S}$ bifrustum nanocrystals were prepared according to the method described in the literature. ${ }^{16}$ Typically, $0.203 \mathrm{~g}$ of $\mathrm{CuSO}_{4} \cdot 5 \mathrm{H}_{2} \mathrm{O}, 6 \mathrm{~mL}$ of OA, and $7.5 \mathrm{~mL}$ of DDT were brought into a three-neck round-bottom flask, connected to a Schlenk line. Under constant stirring and nitrogen atmosphere, the mixture was heated to $200{ }^{\circ} \mathrm{C}$ at a rate of about 30 ${ }^{\circ} \mathrm{C} / \mathrm{min}$. After reaction for $2 \mathrm{~h}$ at $200{ }^{\circ} \mathrm{C}$, the mixture was allowed to cool to approximately $110^{\circ} \mathrm{C}$, when it was quenched by injection of 5 $\mathrm{mL}$ of toluene. The product was precipitated by addition of a mixture of methanol and butanol as nonsolvent and isolated by centrifugation at $2500 \mathrm{rpm}$ for $10 \mathrm{~min}$. The supernatant was removed, and the residue was redispersed in toluene. The mass of product was estimated by weighing the empty sample vials prior to sample retrieval and after removal of the supernatant. The amount of toluene used to redisperse the particles was chosen such that a concentration of approximately $20 \mathrm{~g} / \mathrm{L}$ was obtained.

Preparation of Cation Exchange Precursors. Ga- and Inphosphine precursors were prepared in a way similar to our previously reported method. ${ }^{18}$

$\mathrm{InCl}_{3}-\mathrm{TOP}$ was prepared in a $\mathrm{N}_{2}$-filled glovebox, by addition of $1.250 \mathrm{~mL}(2.8 \mathrm{mmol})$ of TOP to an equimolar amount $(0.620 \mathrm{~g})$ of $\mathrm{InCl}_{3}$, followed by heating to $50{ }^{\circ} \mathrm{C}$ under constant stirring. The resulting turbid, white, viscous liquid was diluted by addition of 1.250 $\mathrm{mL}$ of toluene.

$\mathrm{GaCl}_{3}-\mathrm{TOP}$ was prepared in a $\mathrm{N}_{2}$-filled glovebox, by addition of $0.500 \mathrm{~mL}(1.12 \mathrm{mmol})$ TOP to an equimolar amount $(0.197 \mathrm{~g})$ of $\mathrm{GaCl}_{3}$, followed by heating to $50{ }^{\circ} \mathrm{C}$ under constant stirring, yielding a transparent, orange, viscous liquid.

$\mathrm{GaCl}_{3}$-DPP was prepared in a $\mathrm{N}_{2}$-filled glovebox, by addition of $0.815 \mathrm{~mL}(4.683 \mathrm{mmol}) \mathrm{DPP}$ to an equimolar amount $(0.8246 \mathrm{~g})$ of $\mathrm{GaCl}_{3}$, followed by heating to $50{ }^{\circ} \mathrm{C}$ under constant stirring. After a few minutes, an opaque, white, viscous liquid formed. Over the course of several hours, the liquid changed into an opaque, white, crystalline solid, which was dissolved in $10 \mathrm{~mL}$ of toluene at $100{ }^{\circ} \mathrm{C}$.

$\mathrm{GaCl}_{3}-\mathrm{TPP}$ was prepared in a $\mathrm{N}_{2}$-filled glovebox, by addition of $1.125 \mathrm{~mL}(4.281 \mathrm{mmol}) \mathrm{TPP}$ to an equimolar amount $(0.7538 \mathrm{~g})$ of $\mathrm{GaCl}_{3}$, followed by heating to $50{ }^{\circ} \mathrm{C}$ under constant stirring. After a few minutes, an opaque, white, crystalline solid formed, which was dissolved in $10 \mathrm{~mL}$ of toluene at $100{ }^{\circ} \mathrm{C}$.

$\mathrm{GaCl}_{3}$ cation exchange precursor was prepared in a $\mathrm{N}_{2}$-filled glovebox, by making a $1 \mathrm{~mol} / \mathrm{L}(176.08 \mathrm{~g} / \mathrm{L})$ solution of $\mathrm{GaCl}_{3}$ in toluene, resulting in a transparent, bright green liquid. It was found that the solution degraded over time, even when stored under inert atmosphere. Degradation was indicated by a change of color from bright green to dark red. In all reactions with $\mathrm{GaCl}_{3}$ as precursor, a fresh batch of precursor was used.

Cation Exchange in $\mathrm{Cu}_{2-x} \mathrm{~S}$ Bifrustum Nanocrystals. The cation exchange reactions were performed following the method reported in ref 18 inside a $\mathrm{N}_{2}$-filled glovebox. The equivalent of 0.2 mmol cation exchange precursor $\left(0.200 \mathrm{~mL}\right.$ of $\mathrm{InCl}_{3}-\mathrm{TOP}, 0.100 \mathrm{~mL}$ of $\mathrm{GaCl}_{3}$-TOP, $0.425 \mathrm{~mL}$ of $\mathrm{GaCl}_{3}-\mathrm{DPP}, 0.465 \mathrm{~mL}$ of $\mathrm{GaCl}_{3}-\mathrm{TPP}$, $0.200 \mathrm{~mL}$ of $\mathrm{GaCl}_{3}$ solution) was placed in a vial. Toluene was added to make the total reaction volume after addition of the $\mathrm{NC}$ dispersion $2.700 \mathrm{~mL}$ (added volume: with $\mathrm{InCl}_{3}-\mathrm{TOP}, 2.000 \mathrm{~mL}$; with $\mathrm{GaCl}_{3}-$ 
TOP, $2.100 \mathrm{~mL}$; with $\mathrm{GaCl}_{3}-\mathrm{DPP}, 1.775 \mathrm{~mL}$; with $\mathrm{GaCl}_{3}-\mathrm{TPP}$, $1.735 \mathrm{~mL}$; with $\mathrm{GaCl}_{3}, 2.000 \mathrm{~mL}$ ). The mixture of toluene and cation exchange precursor was heated to the reaction temperature $\left(100{ }^{\circ} \mathrm{C}\right.$ with $\mathrm{InCl}_{3}$-TOP, $\mathrm{GaCl}_{3}$-TOP, $\mathrm{GaCl}_{3}-\mathrm{DPP}, \mathrm{GaCl}_{3}-\mathrm{TPP}$ and $30^{\circ} \mathrm{C}$ with $\mathrm{GaCl}_{3}$ ) under constant stirring at $400 \mathrm{rpm}$. Once the desired temperature was reached, $0.500 \mathrm{~mL}$ of parent $\mathrm{NC}$ dispersion (equivalent to approximately $10 \mathrm{mg}$ of parent particles) was swiftly injected. The reaction was stopped (reaction time: with $\mathrm{InCl}_{3}-\mathrm{TOP}$, overnight; with $\mathrm{GaCl}_{3}-\mathrm{TOP}$, overnight; with $\mathrm{GaCl}_{3}-\mathrm{TPP}, 60$ min; with $\mathrm{GaCl}_{3}-\mathrm{DPP}, 60 \mathrm{~min}$; with $\mathrm{GaCl}_{3}, 15,30,60,120$, and $300 \mathrm{~min}$ ) by removing the vial from the heater and quenched by the addition of methanol and butanol as nonsolvents. All samples were washed at least twice prior to analysis, by addition of methanol and butanol as nonsolvent, centrifugation and removal of the supernatant. Finally, the particles were redispersed in toluene.

Cation Exchange under Milder Reaction Conditions with $\mathrm{GaCl}_{3}$-DPP. To prevent particle agglomeration, the reaction of $\mathrm{Cu}_{2-x} \mathrm{~S}$ nanocrystals with $\mathrm{GaCl}_{3}-\mathrm{DPP}$ was also performed under milder reaction conditions. This reaction was performed at half the scale of the reactions discussed above, inside a $\mathrm{N}_{2}$-filled glovebox. To this end, $0.1 \mathrm{mmol}(0.210 \mathrm{~mL}) \mathrm{GaCl}_{3}-\mathrm{DPP}, 0.860 \mathrm{~mL}$ of toluene, and $0.025 \mathrm{~mL}$ of OLAM were placed in a vial. The mixture was heated to $50{ }^{\circ} \mathrm{C}$, under constant stirring at $400 \mathrm{rpm}$. Once the desired temperature was reached, $0.250 \mathrm{~mL}$ of parent $\mathrm{NC}$ dispersion (equivalent to approximately $5 \mathrm{mg}$ of parent particles) was swiftly injected. The reaction was stopped by removing the vial from the heater and quenched by the addition of methanol and butanol as nonsolvents. The product was washed twice prior to analysis, by addition of methanol and butanol as nonsolvent, centrifugation, and removal of the supernatant. Finally, the particles were redispersed in toluene.

Synthesis of CulnS ${ }_{2}$ NCs. For the synthesis of luminescent $\mathrm{CuInS}_{2}$ (CIS) NCs a protocol reported earlier by Li et al. ${ }^{66}$ was adapted. Briefly, $297 \mathrm{mg}$ of $\operatorname{In}(\mathrm{Ac})_{3}, 191 \mathrm{mg}$ of CuI, and $5 \mathrm{~mL}$ of DDT were mixed and degassed under vacuum for $1 \mathrm{~h}$ at $80^{\circ} \mathrm{C}$. The reaction mixture was then heated under $\mathrm{N}_{2}$ flow to $230{ }^{\circ} \mathrm{C}$ and allowed to react for $100 \mathrm{~min}$. The reaction was stopped by removing the heating mantle. The NCs were precipitated with a methanol/ butanol $1 / 1$ mixture and, after centrifugation and decanting the supernatant, dispersed in $10 \mathrm{~mL}$ of toluene.

Cation Exchange in CulnS, NCs. CIS NCs $(0.250 \mathrm{~mL})$ in toluene were diluted in a vial with $1 \mathrm{~mL}$ of toluene and mixed with 0.1 $\mathrm{mL}$ of DDT (extra ligand) and $0.1 \mathrm{~mL}$ of $\mathrm{GaCl}_{3}-\mathrm{DPP}$ (prepared as described above, however, not dissolved in toluene), which was melted at a heating plate with a plate temperature of $100^{\circ} \mathrm{C}$. The vial containing this mixture was placed on the heating plate with $T_{\text {plate }}=$ $100{ }^{\circ} \mathrm{C}$ for $30 \mathrm{~min}$, after which the vial was removed and the NCs were precipitated with a methanol/butanol $1 / 1$ mixture and, after centrifugation and decanting the supernatant, dispersed in $0.2 \mathrm{~mL}$ of toluene.

Optical Spectroscopy. Samples were prepared by placing a diluted dispersion of nanocrystals in toluene in a quartz cuvette with $10 \mathrm{~mm}$ path length. Absorption spectra were measured using a PerkinElmer Lambda 16 UV-vis-NIR spectrometer. Photoluminescence spectra were measured on an Edinburgh Instruments FLS920 spectrofluorimeter equipped with a Hamamatsu R5509-72 PMT with a monochromator grated at $1200 \mathrm{~nm}$. A $900 \mathrm{~W}$ Xe lamp was used as the excitation source.

Transmission Electron Microscopy. TEM images were recorded on Thermo Fisher Scientific (formerly Philips/FEI) Tecnai 10, Tecnai 12, and Tecnai 20 electron microscopes. TEM samples were prepared by drop-casting a dispersion of particles in toluene onto a copper TEM grid, with a carbon-coated polymer support film.

Energy-Dispersive X-ray Spectroscopy. EDS measurements were performed on Thermo Fisher Scientific Tecnai 20F and Talos F200X electron microscopes using Tecnai Imaging and Analysis software. Sample preparation was similar to the preparation of TEM samples. In all cases, aluminum TEM grids were used. A lowbackground sample holder was used. Measurements were performed on areas with $>500$ nanoparticles. Discussed elemental compositions are normalized to the stoichiometric sulfur contents.

Elemental Mapping. Elemental mapping was performed on a Talos F200X electron microscope equipped with a $200 \mathrm{kV}$ XFEG. Xray detection was done using four symmetrically placed SuperX-EDX detectors. Imaging was performed in high-angle annular dark-field scanning transmission electron microscopy mode, with a current of $700 \mathrm{pA}$ using a Fischione Instruments HAADF detector. Obtained data were analyzed using Bruker Esprit software.

HAADF-STEM Tomography. Tilt series for HAADF-STEM tomography were acquired with a FEI Tecnai Osiris operated at $200 \mathrm{kV}$ in combination with an advanced tomography holder from Fischione Instruments and the FEI XPlore3D acquisition software. Tilt series consisting of 31 HAADF-STEM images were acquired with tilt increments of $5^{\circ}$ over a range of $\pm 75^{\circ}$. Alignment of the data was carried out using the FEI Inspect3D software package. The reconstruction was performed using the simultaneous iterative reconstruction technique, with 25 iterations, implemented in Inspect3D. Amira (Visage Imaging $\mathrm{GmbH}$ ) was used for the visualization of the reconstructed volume.

Electron Diffraction. Due to the large amount of sample required for X-ray diffraction (XRD) measurements and low signal-to-noise ratio in XRD measurements for the samples presented in this work, ED was used instead to determine the crystal structure and crystallinity of the samples. ED patterns were measured on a Tecnai 12 electron microscope with an acceleration voltage of $120 \mathrm{kV}$ at a camera length of $1 \mathrm{~m}$.

Data processing of ED patterns measured on $\mathrm{Cu}_{2-x} \mathrm{~S}$ NCs and the particles obtained after reaction of these parent NCs with cation exchange precursors was performed as follows: measured twodimensional patterns were reduced to one dimension by azimuthal integration of the patterns around the center, which was manually defined for every pattern. The measured ED patterns were calibrated to a gold reference sample (Agar S106). The calibration procedure is described in detail in the Supporting Information.

Data processing of ED patterns measured on CIS NCs and the particles obtained after reaction of these parent NCs with cation exchange precursors, was performed using the Crystallographic Tool Box (CrysTBox) software, ${ }^{70}$ which automatically performed the required steps of center localization, azimuthal integration, and calibration to a gold reference sample.

Calculated Diffraction Patterns. Diffraction patterns for the low-chalcocite $\mathrm{Cu}_{2-x} \mathrm{~S}$ and wurtzite $\mathrm{CuGaS}_{2}$ crystal structures were calculated from the relevant crystal structures (for low-chalcocite $\mathrm{Cu}_{2-x} \mathrm{~S}$, the crystal structure reported in ref 34; for wurtzite CGS, the crystal structure reported in ref 44) using the Visualization for Electronic and Structural Analysis (VESTA) software program (version 3.3.9), ${ }^{71}$ using the default settings. The calculated lattice distances in real space, $d$, were transformed into distances in reciprocal space, $q$, using the equation $q=2 \pi / d$.

Comparison of the Anion Sublattices. Using the VESTA software program, ${ }^{71}$ all cations were removed from the crystal structures of low-chalcocite $\mathrm{Cu}_{2-x} \mathrm{~S},{ }^{34}$ wurtzite CGS, ${ }^{44}$ and monoclinic $\alpha^{\prime}-\mathrm{Ga}_{2} \mathrm{~S}_{3},{ }^{46}$ and a supercell (consisting of multiple unit cells) was constructed. Data corresponding to a single hexagonal layer and a single ...ABAB... layer was exported for each crystal structure. The anion coordinates were translated and rotated to orient the three data sets in the same manner. In this common orientation, the $x, y$, and $z$ directions correspond to the following crystallographic directions: low-chalcocite $\mathrm{Cu}_{2-x} \mathrm{~S}:[201],[010],[001]$; wurtzite $\mathrm{CuGaS}_{2}$ : [11̄0], $[110],[001]$; monoclinic $\alpha^{\prime}-\mathrm{Ga}_{2} \mathrm{~S}_{3}:[010],[100],[102]$. Lattice distances $\Delta x, \Delta y$, and $\Delta z$ were measured over 5,8 , and 5 anion-anion distances in $x, y$, and $z$, respectively. Relative lattice contraction values, corresponding to a transformation of lattice $A$ into $B$, are defined as $c=\left(1-\frac{\Delta x_{B}}{\Delta x_{A}}\right) \times 100 \%$ (and similarly for the $y$ and $z$ directions).

DFT Calculations. All DFT calculations were performed using the Gaussian 09, revision D.01, software package. ${ }^{72}$ Geometry optimizations were performed using the B3LYP (Becke, three-parameter, Lee-Yang-Parr) functional, the relativistic Stuttgart-Dresden 
(SDD) pseudopotential and basis set on Ga and In and the 6$311+\mathrm{G}(\mathrm{d}, \mathrm{p})$ basis set on all other atoms. The structures were optimized without any symmetry restraints. Frequency analyses at the same level were performed on all calculations to verify that the obtained stationary points are in fact energy minima. Thermochemical analysis was performed using a temperature of 298.15 K. Depicted visualizations of the geometry-optimized structures were prepared using the VESTA software program. ${ }^{71}$

\section{ASSOCIATED CONTENT}

\section{S Supporting Information}

The Supporting Information is available free of charge on the ACS Publications website at DOI: 10.1021/acsnano.9b05337.

NC size histograms, EDS of NCs before and after CE reaction, absorption spectra of NCs before and after $\mathrm{CE}$, TEM images of NCs after reaction with $\mathrm{GaCl}_{3}$ and $\mathrm{GaCl}_{3}-\mathrm{DPP}$ at $100{ }^{\circ} \mathrm{C}$, HAADF-STEM images and EDS elemental maps of $\mathrm{Cu}_{2-x} \mathrm{~S}$ NCs after reaction with $\mathrm{GaCl}_{3}$, detailed description of PED calibration procedure (PDF)

File showing the results of the DFT calculations (ground-state geometries and bond enthalpies for the phosphine complexes used in our work (XYZ)

\section{(W Web-Enhanced Features}

Animated versions of the $3 \mathrm{D}$ tomographic reconstructions shown in Figure 3.

\section{AUTHOR INFORMATION}

\section{Corresponding Author}

*E-mail: c.demello-donega@uu.nl.

\section{ORCID}

Stijn O. M. Hinterding: 0000-0002-3940-1253

Sara Bals: 0000-0002-4249-8017

Ward van der Stam: 0000-0001-8155-5400

Celso de Mello Donega: 0000-0002-4403-3627

\section{Present Addresses}

${ }^{\perp}$ S.O.M.H.: Soft Condensed Matter/Inorganic Chemistry and Catalysis, Debye Institute for Nanomaterials Science, Utrecht University, P.O. Box 80000, 3508 TA Utrecht, The Netherlands.

IIA.C.B.: Seaborough Research B.V., Science Park 106, 1098XG Amsterdam, The Netherlands.

${ }^{\#}$ M.K.: Foseco Nederland B.V., Pantheon 30, 7521PR Enschede, The Netherlands.

$\boldsymbol{\Delta}_{\text {W.v.d.S.: Inorganic Chemistry and Catalysis, Debye Institute }}$ for Nanomaterials Science, Utrecht University, P.O. Box 80000, Universiteitsweg 99, 3584CG Utrecht, The Netherlands.

\section{Notes}

The authors declare no competing financial interest.

\section{ACKNOWLEDGMENTS}

S.O.M.H., W.v.d.S., A.C.B., and C.d.M.D. acknowledge financial support from the division of Chemical Sciences (CW) of The Netherlands Organization for Scientific Research (NWO) under Grant Nos. ECHO.712.012.0001 and ECHO.712.014.001. S.B. acknowledges financial support from the European Research Council (ERC Consolidator Grant No. 815128-REALNANO). S.O.M.H. is supported by The Netherlands Center for Multiscale Catalytic Energy Conversion (MCEC), an NWO Gravitation Programme funded by the Ministry of Education, Culture and Science of the government of The Netherlands. DFT calculations were carried out on the Dutch national e-infrastructure with the support of SURF Cooperative. This work was sponsored by NWO Physical Sciences for the use of supercomputer facilities. The authors thank Jessi van der Hoeven for EDS and TEM measurements.

\section{REFERENCES}

(1) Van der Stam, W.; Berends, A. C.; de Mello Donegá, C. Prospects of Colloidal Copper Chalcogenide Nanocrystals. ChemPhysChem 2016, 17, 559-581.

(2) Kolny-Olesiak, J.; Weller, H. Synthesis and Application of Colloidal $\mathrm{CuInS}_{2}$ Semiconductor Nanocrystals. ACS Appl. Mater. Interfaces 2013, 5, 12221-12237.

(3) Coughlan, C.; Ibáñez, M.; Dobrozhan, O.; Singh, A.; Cabot, A.; Ryan, K. M. Compound Copper Chalcogenide Nanocrystals. Chem. Rev. 2017, 117, 5865-6109.

(4) Van der Stam, W.; Gudjonsdottir, S.; Evers, W. H.; Houtepen, A. J. Switching between Plasmonic and Fluorescent Copper Sulfide Nanocrystals. J. Am. Chem. Soc. 2017, 139, 13208-13217.

(5) Beberwyck, B. J.; Surendranath, Y.; Alivisatos, A. P. Cation Exchange: A Versatile Tool for Nanomaterials Synthesis. J. Phys. Chem. C 2013, 117, 19759-19770.

(6) Rivest, J. B.; Jain, P. K. Cation Exchange on the Nanoscale: An Emerging Technique for New Material Synthesis, Device Fabrication, and Chemical Sensing. Chem. Soc. Rev. 2013, 42, 89-96.

(7) Gupta, S.; Kershaw, S. V.; Rogach, A. L. 25th Anniversary Article: Ion Exchange in Colloidal Nanocrystals. Adv. Mater. 2013, 25, 6923-6944.

(8) De Trizio, L.; Manna, L. Forging Colloidal Nanostructures via Cation Exchange Reactions. Chem. Rev. 2016, 116, 10852-10887.

(9) Sahu, A.; Kang, M. S.; Kompch, A.; Notthoff, C.; Wills, A. W.; Deng, D.; Winterer, M.; Frisbie, C. D.; Norris, D. J. Electronic Impurity Doping in CdSe Nanocrystals. Nano Lett. 2012, 12, 25872594.

(10) Van der Stam, W.; Geuchies, J. J.; Altantzis, T.; Van den Bos, K. H. W.; Meeldijk, J. D.; Van Aert, S.; Bals, S.; Vanmaekelbergh, D.; de Mello Donegá, C. Highly Emissive Divalent Ion Doped Colloidal $\mathrm{CsPb}_{1-\mathrm{x}} \mathrm{M}_{\mathrm{x}} \mathrm{Br}_{3}$ Perovskite Nanocrystals through Cation Exchange. J. Am. Chem. Soc. 2017, 139, 4087-4097.

(11) Eilers, J.; Groeneveld, E.; de Mello Donegá, C.; Meijerink, A. Optical Properties of Mn-Doped ZnTe Magic Size Nanocrystals. J. Phys. Chem. Lett. 2012, 3, 1663-1667.

(12) Groeneveld, E.; Witteman, L.; Lefferts, M.; Ke, X.; Bals, S.; Van Tendeloo, G.; de Mello Donegá, C. Tailoring ZnSe-CdSe Colloidal Quantum Dots via Cation Exchange: From Core/Shell to Alloy Nanocrystals. ACS Nano 2013, 7, 7913-7930.

(13) Grodzińska, D.; Pietra, F.; Van Huis, M. A.; Vanmaekelbergh, D.; de Mello Donegá, C. Thermally Induced Atomic Reconstruction of $\mathrm{PbSe} / \mathrm{CdSe}$ Core/Shell Quantum Dots into $\mathrm{PbSe} / \mathrm{CdSe} \mathrm{Bi}-$ Hemisphere Hetero-Nanocrystals. J. Mater. Chem. 2011, 21, $11556-$ 11565 .

(14) Fan, Z.; Lin, L.-C.; Buijs, W.; Vlugt, T. J. H.; Van Huis, M. A. Atomistic Understanding of Cation Exchange in $\mathrm{PbS}$ Nanocrystals Using Simulations with Pseudoligands. Nat. Commun. 2016, 7, 11503.

(15) Hewavitharana, I. K.; Brock, S. L. When Ligand Exchange Leads to Ion Exchange: Nanocrystal Facets Dictate the Outcome. ACS Nano 2017, 11, 11217-11224.

(16) Van der Stam, W.; Berends, A. C.; Rabouw, F. T.; Willhammar, T.; Ke, X.; Meeldijk, J. D.; Bals, S.; de Mello Donegá, C. Luminescent $\mathrm{CuInS}_{2}$ Quantum Dots by Partial Cation Exchange in $\mathrm{Cu}_{2-\mathrm{x}} \mathrm{S}$ Nanocrystals. Chem. Mater. 2015, 27, 621-628.

(17) Jharimune, S.; Sathe, A. A.; Rioux, R. M. Thermochemical Measurements of Cation Exchange in CdSe Nanocrystals Using Isothermal Titration Calorimetry. Nano Lett. 2018, 18, 6795-6803.

(18) Van der Stam, W.; Bladt, E.; Rabouw, F. T.; Bals, S.; de Mello Donegá, C. Near-Infrared Emitting $\mathrm{CuInSe}_{2} / \mathrm{CuInS}_{2}$ Dot Core/Rod 
Shell Heteronanorods by Sequential Cation Exchange. ACS Nano 2015, 9, 11430-11438.

(19) Wang, H.; Butler, D. J.; Straus, D. B.; Oh, N.; Wu, F.; Guo, J.; Xue, K.; Lee, J. D.; Murray, C. B.; Kagan, C. R. Air-Stable CuInSe Nanocrystal Transistors and Circuits via Post-Deposition Cation Exchange. ACS Nano 2019, 13, 2324-2333.

(20) Regulacio, M. D.; Ye, C.; Lim, S. H.; Zheng, Y.; Xu, Q.-H.; Han, M.-Y. Facile Noninjection Synthesis and Photocatalytic Properties of Wurtzite-Phase $\mathrm{CuGaS}_{2}$ Nanocrystals with Elongated Morphologies. CrystEngComm 2013, 15, 5214-5217.

(21) Guijarro, N.; Prévot, M. S.; Yu, X.; Jeanbourquin, X. A.; Bornoz, P.; Bourée, W.; Johnson, M.; Le Formal, F.; Sivula, K. A Bottom-Up Approach toward All-Solution-Processed High-Efficiency $\mathrm{Cu}(\mathrm{In}, \mathrm{Ga}) \mathrm{S}_{2}$ Photocathodes for Solar Water Splitting. Adv. Energy Mater. 2016, 6, 1501949.

(22) Lee, K.-H.; Kim, J.-H.; Jang, H. S.; Do, Y. R.; Yang, H. Quantum-Dot-Based White Lighting Planar Source through Downconversion by Blue Electroluminescence. Opt. Lett. 2014, 39, 12081211.

(23) Kim, J.-H.; Lee, K.-H.; Jo, D.-Y.; Lee, Y.; Hwang, J. Y.; Yang, H. Cu-In-Ga-S Quantum Dot Composition-Dependent Device Performance of Electrically Driven Light-Emitting Diodes. Appl. Phys. Lett. 2014, 105, 133104.

(24) Moon, S. H.; Park, S. J.; Kim, S. H.; Lee, M. W.; Han, J.; Kim, J. Y.; Kim, H.; Hwang, Y. J.; Lee, D.-K.; Min, B. K. Monolithic DSSC/ CIGS Tandem Solar Cell Fabricated by a Solution Process. Sci. Rep. 2015, 5, 8970.

(25) Yang, Y.; Chen, Q.; Hsieh, Y.-T.; Song, T.-B.; De Marco, N.; Zhou, H.; Yang, Y. Multilayer Transparent Top Electrode for Solution Processed Perovskite/Cu(In,Ga) $(\mathrm{Se}, \mathrm{S})_{2}$ Four Terminal Tandem Solar Cells. ACS Nano 2015, 9, 7714-7721.

(26) Zhao, J.; Zhang, J.; Wang, W.; Wang, P.; Li, F.; Ren, D.; Si, H.; Sun, X.; Ji, F.; Hao, Y. Facile Synthesis of $\mathrm{CuInGaS}_{2}$ Quantum Dot Nanoparticles for Bilayer-Sensitized Solar Cells. Dalton Trans 2014, 43, 16588-16592.

(27) Dilena, E.; Xie, Y.; Brescia, R.; Prato, M.; Maserati, L.; Krahne, R.; Paolella, A.; Bertoni, G.; Povia, M.; Moreels, I.; Manna, L. $\mathrm{CuIn}_{\mathrm{x}} \mathrm{Ga}_{1-\mathrm{x}} \mathrm{S}_{2}$ Nanocrystals with Tunable Composition and Band Gap Synthesized via a Phosphine-Free and Scalable Procedure. Chem. Mater. 2013, 25, 3180-3187.

(28) Liu, Y.; Yin, D.; Swihart, M. T. Valence Selectivity of Cation Incorporation into Covellite CuS Nanoplatelets. Chem. Mater. 2018, 30, 1399-1407.

(29) Song, J.; Zhang, Y.; Dai, Y.; Hu, J.; Zhu, L.; Xu, X.; Yu, Y.; Li, H.; Yao, B.; Zhou, H. Polyelectrolyte-Mediated Nontoxic Ag$\mathrm{Ga}_{\mathrm{x}} \mathrm{In}_{1-\mathrm{x}} \mathrm{S}_{2}$ QDs/Low-Density Lipoprotein Nanoprobe for Selective 3D Fluorescence Imaging of Cancer Stem Cells. ACS Appl. Mater. Interfaces 2019, 11, 9884-9892.

(30) Zhai, Y.; Flanagan, J. C.; Shim, M. Lattice Strain and Ligand Effects on the Formation of $\mathrm{Cu}_{2-\mathrm{x}} \mathrm{S} / \mathrm{I}-\mathrm{III}-\mathrm{VI}_{2}$ Nanorod Heterostructures through Partial Cation Exchange. Chem. Mater. 2017, 29, 6161-6167.

(31) Shannon, R. D. Revised Effective Ionic Radii and Systematic Studies of Interatomic Distances. Acta Crystallogr., Sect. A: Cryst. Phys., Diffr., Theor. Gen. Crystallogr. 1976, 32, 751-767.

(32) Pearson, R. G. Absolute Electronegativity and Hardness: Application to Inorganic Chemistry. Inorg. Chem. 1988, 27, 734-740. (33) Xia, C.; Wu, W.; Yu, T.; Xie, X.; Van Oversteeg, C.; Gerritsen, H. C.; de Mello Donegá, C. Size-Dependent Band-Gap and Molar Absorption Coefficients of Colloidal $\mathrm{CuInS}_{2}$ Quantum Dots. ACS Nano 2018, 12, 8350-8361.

(34) Evans, H. T. Crystal Structure of Low Chalcocite. Nature, Phys. Sci. 1971, 232, 69-70.

(35) Wang, W.; Dahl, M.; Yin, Y. Hollow Nanocrystals through the Nanoscale Kirkendall Effect. Chem. Mater. 2013, 25, 1179-1189.

(36) Yin, Y.; Rioux, R. M.; Erdonmez, C. K.; Hughes, S.; Somorjai, G. A.; Alivisatos, A. P. Formation of Hollow Nanocrystals through the Nanoscale Kirkendall Effect. Science 2004, 304, 711-714.
(37) Mu, L.; Wang, F.; Sadtler, B.; Loomis, R. A.; Buhro, W. E. Influence of the Nanoscale Kirkendall Effect on the Morphology of Copper Indium Disulfide Nanoplatelets Synthesized by Ion Exchange. ACS Nano 2015, 9, 7419-7428.

(38) Ogawa, A.; Fujimoto, H. Lewis Acidity of Gallium Halides. Inorg. Chem. 2002, 41, 4888-4894.

(39) Hogg, J. M.; Coleman, F.; Ferrer-Ugalde, A.; Atkins, M. P.; Swadźba-Kwaśny, M. Liquid Coordination Complexes: A New Class of Lewis Acids as Safer Alternatives to $\mathrm{BF}_{3}$ in Synthesis of Polyalphaolefins. Green Chem. 2015, 17, 1831-1841.

(40) Ruberu, T. P. A.; Albright, H. R.; Callis, B.; Ward, B.; Cisneros, J.; Fan, H.-J.; Vela, J. Molecular Control of the Nanoscale: Effect of Phosphine-Chalcogenide Reactivity on CdS-CdSe Nanocrystal Composition and Morphology. ACS Nano 2012, 6, 5348-5359.

(41) Tolman, C. A. Steric Effects of Phosphorus Ligands in Organometallic Chemistry and Homogeneous Catalysis. Chem. Rev. 1977, 77, 313-348.

(42) Kühl, O. Predicting the Net Donating Ability of Phosphines Do We Need Sophisticated Theoretical Methods? Coord. Chem. Rev. 2005, 249, 693-704.

(43) Brown, T. L.; Lee, K. J. Ligand Steric Properties. Coord. Chem. Rev. 1993, 128, 89-116.

(44) Xiao, N.; Zhu, L.; Wang, K.; Dai, Q.; Wang, Y.; Li, S.; Sui, Y.; Ma, Y.; Liu, J.; Liu, B.; Zou, G.; Zou, B. Synthesis and High-Pressure Transformation of Metastable Wurtzite-Structured $\mathrm{CuGaS}_{2}$ Nanocrystals. Nanoscale 2012, 4, 7443-7447.

(45) Fenton, J. L.; Steimle, B. C.; Schaak, R. E. Structure-Selective Synthesis of Wurtzite and Zincblende $\mathrm{ZnS}, \mathrm{CdS}$, and $\mathrm{CuInS}_{2}$ Using Nanoparticle Cation Exchange Reactions. Inorg. Chem. 2019, 58, 672-678.

(46) Pardo, M. P.; Guittard, M.; Chilouet, A.; Tomas, A. Diagramme de Phases Gallium-Soufre et Études Structurales Des Phases Solides. J. Solid State Chem. 1993, 102, 423-433.

(47) Nogai, S.; Schmidbaur, H. Dichlorogallane $\left(\mathrm{HGaCl}_{2}\right)_{2}$ : Its Molecular Structure and Synthetic Potential. Inorg. Chem. 2002, 41, 4770-4774.

(48) Cheng, F.; Codgbrook, H. L.; Hector, A. L.; Levason, W.; Reid, G.; Webster, M.; Zhang, W. Gallium(III) Halide Complexes with Phosphines, Arsines and Phosphine Oxides - a Comparative Study. Polyhedron 2007, 26, 4147-4155.

(49) Yarema, O.; Yarema, M.; Wood, V. Tuning the Composition of Multicomponent Semiconductor Nanocrystals: The Case of I-III-VI Materials. Chem. Mater. 2018, 30, 1446-1461.

(50) Berends, A. C.; Van der Stam, W.; Akkerman, Q. A.; Meeldijk, J. D.; Van der Lit, J.; de Mello Donegá, C. Anisotropic 2D $\mathrm{Cu}_{2-\mathrm{x}} \mathrm{Se}$ Nanocrystals from Dodecaneselenol and Their Conversion to CdSe and CuInSe $e_{2}$ Nanoparticles. Chem. Mater. 2018, 30, 3836-3846.

(51) Tan, J. M. R.; Scott, M. C.; Hao, W.; Baikie, T.; Nelson, C. T.; Pedireddy, S.; Tao, R.; Ling, X.; Magdassi, S.; White, T.; Li, S.; Minor, A. M.; Zheng, H.; Wong, L. H. Revealing Cation-Exchange-Induced Phase Transformations in Multielemental Chalcogenide Nanoparticles. Chem. Mater. 2017, 29, 9192-9199.

(52) Lesnyak, V.; Brescia, R.; Messina, G. C.; Manna, L. Cu Vacancies Boost Cation Exchange Reactions in Copper Selenide Nanocrystals. J. Am. Chem. Soc. 2015, 137, 9315-9323.

(53) Fenton, J. L.; Steimle, B. C.; Schaak, R. E. Tunable Intraparticle Frameworks for Creating Complex Heterostructured Nanoparticle Libraries. Science 2018, 360, 513-517.

(54) Li, H.; Brescia, R.; Krahne, R.; Bertoni, G.; Alcocer, M. J. P.; D’Andrea, C.; Scotognella, F.; Tassone, F.; Zanella, M.; De Giorgi, M.; Manna, L. Blue-UV-Emitting $\mathrm{ZnSe}(\mathrm{Dot}) / \mathrm{ZnS}$ (Rod) Core/Shell Nanocrystals Prepared from CdSe/CdS Nanocrystals by Sequential Cation Exchange. ACS Nano 2012, 6, 1637-1647.

(55) Chakraborty, P.; Jin, Y.; Barrows, C. J.; Dunham, S. T.; Gamelin, D. R. Kinetics of Isovalent $\left(\mathrm{Cd}^{2+}\right)$ and Aliovalent $\left(\mathrm{In}^{3+}\right)$ Cation Exchange in $\mathrm{Cd}_{1-\mathrm{x}} \mathrm{Mn}_{\mathrm{x}} \mathrm{Se}$ Nanocrystals. J. Am. Chem. Soc. 2016, $138,12885-12893$. 
(56) Zuckerman, J. J.; Hagen, A. P. Inorganic Reactions and Methods: Formation of Bonds to O, S, Se, Te, Po (Part 1), 1st ed.; VCH Publishers, Inc.: New York, 1992; Vol. 5, p 217.

(57) Burt, J.; Levason, W.; Reid, G. Coordination Chemistry of the Main Group Elements with Phosphine, Arsine and Stibine Ligands. Coord. Chem. Rev. 2014, 260, 65-115.

(58) Chen, F.; Ma, G.; Bernard, G. M.; Wasylishen, R. E.; Cavell, R. G.; McDonald, R.; Ferguson, M. J. An Investigation of 1:1 Adducts of Gallium Trihalides with Triarylphosphines by Solid-State ${ }^{69 / 71} \mathrm{Ga}$ and

${ }^{31}$ P NMR Spectroscopy. Chem. - Eur. J. 2013, 19, 2826-2838.

(59) Haynes, W. M. CRC Handbook of Chemistry and Physics, 95th ed.; CRC Press: Boca Raton, FL, 2014; section 5-11.

(60) Clavier, H.; Nolan, S. P. Percent Buried Volume for Phosphine and N-Heterocyclic Carbene Ligands: Steric Properties in Organometallic Chemistry. Chem. Commun. (Cambridge, U. K.) 2010, 46, 841-861.

(61) Snelders, D. J. M.; Van Koten, G.; Klein Gebbink, R. J. M. Steric, Electronic, and Secondary Effects on the Coordination Chemistry of Ionic Phosphine Ligands and the Catalytic Behavior of Their Metal Complexes. Chem. - Eur. J. 2011, 17, 42-57.

(62) Chakraborty, P.; Jin, Y.; Barrows, C. J.; Dunham, S. T.; Gamelin, D. R. Kinetics of Isovalent $\left(\mathrm{Cd}^{2+}\right)$ and Aliovalent $\left(\mathrm{In}^{3+}\right)$ Cation Exchange in $\mathrm{Cd}_{1-\mathrm{x}} \mathrm{Mn}_{\mathrm{x}} \mathrm{Se}$ Nanocrystals. J. Am. Chem. Soc. 2016, $138,12885-12893$.

(63) Choi, Y.-M.; Lee, Y.-I.; Kim, S.; Choa, Y.-H. Metallic Alloy Nanoparticle-Based Fabrication and Optical Properties of a $\mathrm{Cu}$ $\left(\operatorname{In}_{1-\mathrm{x}} \mathrm{Ga}_{\mathrm{x}}\right) \mathrm{S}_{2}$ Absorber Layer for Solar Cells. J. Alloys Compd. 2014, 615, 496-500.

(64) Chang, S.-H.; Chiang, M.-Y.; Chiang, C.-C.; Yuan, F.-W.; Chen, C.-Y.; Chiu, B.-C.; Kao, T.-L.; Lai, C.-H.; Tuan, H.-Y. Facile Colloidal Synthesis of Quinary CuIn ${ }_{1-\mathrm{x}} \mathrm{Ga}_{\mathrm{x}}\left(\mathrm{S}_{\mathrm{y}} \mathrm{Se}_{1-\mathrm{y}}\right.$ ) (CIGSSe) Nanocrystal Inks with Tunable Band Gaps for Use in Low-Cost Photovoltaics. Energy Environ. Sci. 2011, 4, 4929-4932.

(65) Xia, C.; Meeldijk, J. D.; Gerritsen, H. C.; de Mello Donegá, C. Highly Luminescent Water-Dispersible NIR-Emitting Wurtzite $\mathrm{CuInS}_{2} / \mathrm{ZnS}$ Core/Shell Colloidal Quantum Dots. Chem. Mater. 2017, 29, 4940-4951.

(66) Li, L.; Pandey, A.; Werder, D. J.; Khanal, B. P.; Pietryga, J. M.; Klimov, V. I. Efficient Synthesis of Highly Luminescent Copper Indium Sulfide-Based Core/Shell Nanocrystals with Surprisingly Long-Lived Emission. J. Am. Chem. Soc. 2011, 133, 1176-1179.

(67) Berends, A. C.; Rabouw, F. T.; Spoor, F. C. M.; Bladt, E.; Grozema, F. C.; Houtepen, A. J.; Siebbeles, L. D. A.; De Mello Donegá, C. Radiative and Nonradiative Recombination in $\mathrm{CuInS}_{2}$ Nanocrystals and $\mathrm{CuInS}_{2}$-Based Core/Shell Nanocrystals. J. Phys. Chem. Lett. 2016, 7, 3503-3509.

(68) Bai, X.; Purcell-Milton, F.; Gun'ko, Y. Optical Properties, Synthesis, and Potential Applications of Cu-Based Ternary or Quaternary Anisotropic Quantum Dots, Polytypic Nanocrystals, and Core/Shell Heterostructures. Nanomaterials 2019, 9, 85.

(69) Berends, A. C.; Mangnus, M. J. J.; Xia, C.; Rabouw, F. T.; De Mello Donegá, C. Optoelectronic Properties of Ternary I-III-VI Semiconductor Nanocrystals: Bright Prospects with Elusive Origins. J. Phys. Chem. Lett. 2019, 10, 1600-1616.

(70) Klinger, M.; Jäger, A. Crystallographic Tool Box (CrysTBox): Automated Tools for Transmission Electron Microscopists and Crystallographers. J. Appl. Crystallogr. 2015, 48, 2012-2018.

(71) Momma, K.; Izumi, F. VESTA 3 for Three-Dimensional Visualization of Crystal, Volumetric and Morphology Data. J. Appl. Crystallogr. 2011, 44, 1272-1276.

(72) Frisch, M. J.; Trucks, G. W.; Schlegel, H. B.; Scuseria, G. E.; Robb, M. A.; Cheeseman, J. R.; Scalmani, G.; Barone, V.; Mennucci, B.; Petersson, G. A.; Nakatsuji, H.; Caricato, M.; Li, X.; Hratchian, H. P.; Izmaylov, A. F.; Bloino, J.; Zheng, G.; Sonnenberg, J. L.; Hada, M.; Ehara, M.; et al. Gaussian 09; Gaussian Inc.: Wallingford, CT, 2009. 